\title{
Evaluating the effects of China's pollution controls on inter-annual trends and uncertainties of atmospheric mercury emissions
}

\author{
Y. Zhao ${ }^{1,2}$, H. Zhong ${ }^{1}$, J. Zhang ${ }^{2,3}$, and C. P. Nielsen ${ }^{4}$ \\ ${ }^{1}$ State Key Laboratory of Pollution Control \& Resource Reuse and School of the Environment, Nanjing University, \\ 163 Xianlin Ave., Nanjing, Jiangsu 210023, China \\ ${ }^{2}$ Collaborative Innovation Center of Atmospheric Environment and Equipment Technology, CICAEET, \\ Nanjing, Jiangsu 210044, China \\ ${ }^{3}$ Jiangsu Provincial Academy of Environmental Science, 176 North Jiangdong Rd., Nanjing, Jiangsu 210036, China \\ ${ }^{4}$ Harvard China Project, School of Engineering and Applied Sciences, Harvard University, 29 Oxford St, \\ Cambridge, MA 02138, USA
}

Correspondence to: Y. Zhao (yuzhao@nju.edu.cn)

Received: 20 September 2014 - Published in Atmos. Chem. Phys. Discuss.: 27 October 2014

Revised: 25 March 2015 - Accepted: 10 April 2015 - Published: 29 April 2015

\begin{abstract}
China's anthropogenic emissions of atmospheric mercury $(\mathrm{Hg})$ are effectively constrained by national air pollution control and energy efficiency policies. In this study, improved methods, based on available data from domestic field measurements, are developed to quantify the benefits of $\mathrm{Hg}$ abatement by various emission control measures. Those measures include increased use of (1) flue gas desulfurization (FGD) and selective catalyst reduction (SCR) systems in power generation; (2) precalciner kilns with fabric filters (FF) in cement production; (3) mechanized coking ovens with electrostatic precipitators (ESP) in iron and steel production; and (4) advanced production technologies in nonferrous metal smelting. Investigation reveals declining trends in emission factors for each of these sources, which together drive a much slower growth of total $\mathrm{Hg}$ emissions than the growth of China's energy consumption and economy, from 679 metric tons (t) in 2005 to $750 \mathrm{t}$ in 2012. In particular, estimated emissions from the above-mentioned four source types declined $3 \%$ from 2005 to 2012, which can be attributed to expanded deployment of technologies with higher energy efficiencies and air pollutant removal rates. Emissions from other anthropogenic sources are estimated to increase by $22 \%$ during the period. The species shares of total $\mathrm{Hg}$ emissions have been stable in recent years, with mass fractions of around 55, 39, and $6 \%$ for gaseous elemental $\mathrm{Hg}$ $\left(\mathrm{Hg}^{0}\right)$, reactive gaseous mercury $\left(\mathrm{Hg}^{2+}\right)$, and particle-bound mercury $\left(\mathrm{Hg}^{\mathrm{p}}\right)$, respectively. The higher estimate of total $\mathrm{Hg}$
\end{abstract}

emissions than previous inventories is supported by limited simulation of atmospheric chemistry and transport. With improved implementation of emission controls and energy saving, a $23 \%$ reduction in annual $\mathrm{Hg}$ emissions from 2012 to 2030 , to below $600 \mathrm{t}$, is expected at the most. While growth in $\mathrm{Hg}$ emissions has been gradually constrained, uncertainties quantified by Monte Carlo simulation for recent years have increased, particularly for the power sector and particular industrial sources. The uncertainty (expressed as $95 \%$ confidence intervals) of $\mathrm{Hg}$ emissions from coal-fired power plants, for example, increased from $-48-+73 \%$ in 2005 to $-50-+89 \%$ in 2012 . This is attributed mainly to increased penetration of advanced manufacturing and pollutant control technologies; the unclear operational status and relatively small sample sizes of field measurements of those processes have resulted in lower but highly varied emission factors. To reduce uncertainty and further confirm the benefits of pollution control and energy polices, therefore, systematic investigation of specific $\mathrm{Hg}$ pollution sources is recommended. The variability of temporal trends and spatial distributions of $\mathrm{Hg}$ emissions needs to be better tracked during the ongoing dramatic changes in China's economy, energy use, and air pollution status. 


\section{Introduction}

Increasing international efforts have been made to study and control the emissions of mercury $(\mathrm{Hg})$, a pollutant well known for its toxicity and long-range transport. Atmospheric emissions are identified as the most significant pathway of $\mathrm{Hg}$ release into the environment (Pirrone and Mason, 2009). In contrast to other heavy metals that are mainly associated with air particles, atmospheric $\mathrm{Hg}$ includes several forms: gaseous elemental $\mathrm{Hg}\left(\mathrm{GEM}, \mathrm{Hg}^{0}\right)$, which has the longest atmospheric lifetime and transport distance; reactive gaseous mercury $\left(\mathrm{RGM}, \mathrm{Hg}^{2+}\right)$, which is generally derived from more local sources; and particle-bound mercury $\left(\mathrm{PBM}, \mathrm{Hg}^{\mathrm{p}}\right)$.

Available global emission inventories indicate that China has become the highest ranking nation in anthropogenic $\mathrm{Hg}$ emissions, attributed mainly to intensive use of fossil fuels to serve a large and rapidly growing economy (Fu et al., 2012a; Pacyna et al., 2010; Pirrone et al., 2010). Pacyna et al. (2010) calculated China's $\mathrm{Hg}$ emissions from fossil fuel use at 400 metric tons (t) in 2005, almost half of the country's anthropogenic emissions. Domestic field measurements or investigations of $\mathrm{Hg}$ emissions have also been conducted for other sources including cement production ( $\mathrm{Li}, 2011)$, metals mining and smelting (P. Li et al., 2009; Li et al., 2012, 2010; Wang et al., 2010a; Wu et al., 2012), solid waste incineration (L. Chen et al., 2013; Hu et al., 2012) and biomass burning (C. Chen et al., 2013; Huang et al., 2011). Most current inventories, however, did not sufficiently consider the differences in application of technologies, or made full use of country- or region-dependent information related to emissions. Global emission factors were applied instead to many sectors. As stressed by AMAP/UNEP (2013), research on the industrial processes and technologies employed to reduce $\mathrm{Hg}$ emissions in different industries, and more importantly in specific countries, is a priority to improve estimation of $\mathrm{Hg}$ emissions.

Under strong pressure to improve air quality (and to strengthen energy security and limit carbon emissions), China's government has been implementing a series of measures to conserve energy and control emissions. Since 2005, for example, small and inefficient plants or boilers in the power sector and certain heavy industrial sectors including cement and steel production have been gradually replaced with larger, energy-efficient units that include advanced dust collectors. Installation of flue gas desulfurization (FGD) systems have been compulsory at all new thermal power units to abate $\mathrm{SO}_{2}$ emissions, and the FGD penetration has increased from $13 \%$ of total thermal power capacity in 2005 to $86 \%$ in 2010 (Zhao et al., 2008, 2013). Since 2010, selective catalyst reduction (SCR) systems have been increasingly installed in power plants to reduce $\mathrm{NO}_{x}$ emissions, and the penetration is expected to rise from $10 \%$ in 2010 to $70 \%$ in 2015 (Wang, 2013). The 2013 announcement of a national action plan of air pollution control, responding to recent severe urban haze episodes, will result in further advances in emission abate- ment and air quality in the future (Zhao et al., 2014). Although designed to target other pollutants, all of these measures have ancillary benefits to atmospheric $\mathrm{Hg}$ abatement. For example, the use of advanced dust collectors (e.g., fabric filters, FF, and electrostatic precipitators, ESP) and FGD are expected to significantly reduce emission levels (USEPA, 2002a; Wang et al., 2010b). SCR catalysts convert part of the $\mathrm{Hg}^{0}$ to $\mathrm{Hg}^{2+}$, which is more liable to be absorbed by the FGD scrubber (Wang et al., 2012; Tian et al., 2012). Failure to track and evaluate such swift changes in emission sources and control technologies will lead to less accurate estimates of the trends in China's $\mathrm{Hg}$ emissions and its contributions to the global $\mathrm{Hg}$ cycle. Currently, most global estimates of historical and future $\mathrm{Hg}$ emissions show steadily increasing trends, driven mainly by expansion of industry in Asia (Streets et al., 2009a; Driscoll et al., 2013; AMAP/UNEP, 2013). This is inconsistent, however, with declining worldwide trends in background atmospheric $\mathrm{Hg}$ concentrations (Slemr et al., 2011; Ci et al., 2012; Driscoll et al., 2013).

Aside from the implications of recent and future trends, the $\mathrm{Hg}$ emission uncertainties pose further problems to the scientific community. The uncertainties will be transferred by use of the emission estimates in atmospheric chemistry simulations to analyses of transport and deposition of $\mathrm{Hg}$ (Pan et al., 2008; Lin et al., 2010; Corbitt et al., 2011). Despite this, very few countries include quantified uncertainties in their national emission reporting, particularly developing countries with poorer data availability and quality including China (Pacyna et al., 2010; Ci et al., 2012; AMAP/UNEP, 2013). To date, only the uncertainties of emissions from the power sector have been systematically quantified for China (Wu et al., 2010), with the lack of estimates for other sectors attributed mainly to limited information about other emission source types.

This study therefore seeks to assess the effects of recently implemented and ongoing control measures on past and future inter-annual trends and sector distributions of China's anthropogenic $\mathrm{Hg}$ emissions. The uncertainty of emissions is quantified, and the most sensitive parameters identified for improvement of future estimates.

\section{Methodology and data sources}

\subsection{Brief summary of $\mathrm{Hg}$ emission estimation}

The research domain covers the 31 provinces of mainland China. Annual emissions of $\mathrm{Hg}$, including speciated forms $\left(\mathrm{Hg}^{0}, \mathrm{Hg}^{2+}\right.$, and $\left.\mathrm{Hg}^{\mathrm{p}}\right)$, are estimated at the provincial level from 2005 to 2012, to evaluate the effects of China's energy policies and air pollution control measures. The main anthropogenic activities fall into three sector categories: coal-fired power plants (CPP), all other industrial facilities (IND), and the residential and commercial sector (RES). IND is further divided into cement kilns (CEM), iron and steel plants (ISP), 
heating boilers (HB), other industrial boilers (OIB), nonferrous metal smelting plants (NMS), gold mining operations (GM, including large-scale gold mining, LGM, and artisanal and small-scale gold mining, ASGM), and the operations of other miscellaneous processes (OMP). RES mainly includes coal combustion (RC), oil and gas combustion (ROG), biofuel use/biomass open burning (BIO), and solid waste incineration (SWI) subcategories. As the dominant primary energy resource, coal plays important roles in most anthropogenic pollutant emissions in China (Zhao et al., 2013). Therefore, the $\mathrm{Hg}$ emissions from coal use are estimated based on the above-mentioned source categories, e.g., power plants, industrial boilers, residential coal stoves, and iron and steel production (most emissions of which come from coal use). For cement production, $\mathrm{Hg}$ emissions result both from coal combustion and non-combustion processes, and a new method is developed to differentiate the two parts, as described in Sect. 2.2.

In general, annual emissions of total $\mathrm{Hg}$ and the three $\mathrm{Hg}$ species are calculated using Eqs. (1) and (2), respectively, for a given province $i$ and a given year $t$ :

$E_{i, t}=\sum_{m} \sum_{n} \mathrm{AL}_{m, n, i, t} \times \mathrm{EF}_{m, n, i, t}$,

$E_{i, t, \mathrm{~s}}=\sum_{m} \sum_{n} \mathrm{AL}_{m, n, i, t} \times \mathrm{EF}_{m, n, i, t} \times f_{m, n}$,

where $E$ is the $\mathrm{Hg}$ emission; $\mathrm{AL}$ is the activity levels (fuel consumption or industrial production), $\mathrm{EF}$ is the combined emission factor (emissions per unit of activity level); $f$ is the mass fraction of a given $\mathrm{Hg}$ species $\left(\mathrm{Hg}^{0}, \mathrm{Hg}^{2+}\right.$ or $\left.\mathrm{Hg}^{\mathrm{p}}\right)$; and $i, t, m, n$ and s represent province, year, emission source type, technology of manufacturing and emission control, and $\mathrm{Hg}$ species.

For coal combustion, Eq. (1) can be further revised to Eq. (3) with detailed combustor and fuel information:

$E_{i, t}=\sum_{m} \sum_{n} \mathrm{AL}_{m, n, i, t} \times \mathrm{HgC}_{i, t} \times R_{m, n} \times\left(1-\eta_{m, n, t}\right)$,

where $\mathrm{HgC}$ is the $\mathrm{Hg}$ content of coal by province; $R$ is the mass fraction of $\mathrm{Hg}$ released from the fuel; and $\eta$ is $\mathrm{Hg}$ removal efficiency of air pollution control devices.

Due to inadequate information, emissions from ASGM are not calculated based on the emission factors and activity levels. ASGM was officially prohibited in the 1990s, although it may still occur illegally in some areas because of the huge economic profits. Telmer and Veiga (2009) estimated the $\mathrm{Hg}$ release from ASGM in 2008 based on available data on $\mathrm{Hg}$ and gold exports and imports, and the results are widely accepted (AMAP/UNEP, 2013). Muntean et al. (2014) developed a new method to estimate historical trends in ASGM activity, based on the market demand for gold and the relatively accurate data available on large-scale gold production. They found little inter-annual variation after 2005 for China. In this work, therefore, the results by Telmer and Veiga (2009) are directly used for 2005-2012.

Activity levels for 2005-2012 are compiled annually by sector from various data sources. Multiple-year fossil fuel consumption and industrial production at the provincial level are obtained from Chinese official energy (NBS, 2013a) and industrial economic statistics (NBS, 2013b), respectively. The coal consumption in CEM and ISP is calculated following the methods of Zhao et al. (2011, 2012), and the coal consumption by OIB is estimated by subtracting the fuel consumed by CEM, ISP, and HB from that by IND (Zhao et al., 2012). The annual biofuel use until 2008 is taken from official statistics (NBS, 2013a); NBS stopped reporting the data in that year, so estimates for subsequent years are taken from unpublished data of the Ministry of Agriculture (C. Chen et al., 2013). The biomass combusted in open fields is calculated as a product of grain production, waste-to-grain ratio, and the percentage of residual material burned in the field, as described in Zhao et al. (2011, 2012). The burned urban municipal waste is taken from official statistics (NBS, 2013c), and that in rural areas is calculated as a product of rural population, the average waste per capita, and the estimated ratios of waste that is burned (Yao et al., 2009).

The $\mathrm{Hg}$ emission factors, speciation, and the time-series trends due to improved controls will be described by sector in Sect. 3.

\subsection{Improved methods for estimating emissions from particular sources}

The methods of emission estimation for certain sources are improved to better understand the effectiveness of ongoing pollution control measures in China. Those sources include thermal power generation, cement and steel production, and nonferrous metal smelting, emissions of which were estimated in previous studies with uniform, time-independent emission factors averaged at the sector level.

For power plants, detailed information related to emission estimation is compiled at the generating unit level, including coal consumption, combustion technology, fuel quality, and the time and type of emission control technologies applied, based on an updated Chinese power plant database developed by the authors (Zhao et al., 2008). Hg emissions of each plant are then calculated plant-by-plant based on the unit-specific information using Eq. (3).

With improved data on kiln technologies and emission control devices (Lei et al., 2011; Zhao et al., 2013), their penetrations into the cement industry for a range of years are derived. $\mathrm{Hg}$ emission factors by emission control type, based on domestic measurements, are accordingly applied to generate the inter-annual trends in emissions. Besides total emissions of the sector, Eq. (3) is used to separately estimate the emissions from coal combustion in cement industry. For nonferrous metal smelting, similarly, the penetrations of different manufacturing technologies for typical years $(2005,2007$, 
and 2010) are obtained from a plant-by-plant database developed by Tsinghua University (Wu et al., 2012), and penetrations for other years have to be interpolated due to a lack of further information. The inter-annual trends of emissions can then be estimated by combining the penetration and emission factors by technology.

For iron and steel production, $\mathrm{Hg}$ emissions come mainly from coal-combustion processes including coking, sintering, and pig-iron production. In recent years, implementation of national energy-saving and pollution-control policies led to improved energy efficiency and enhanced use of emission control devices of those processes (Zhao et al., 2013). The updated information is integrated into Eq. (3) to estimate the $\mathrm{Hg}$ emissions for the sector by process and year. In particular, the coal consumption by process is calculated based on the amount of coal combusted by the whole sector and the energy efficiency by process (expressed as $\mathrm{kg}$ coal equivalent/t steel) reported in official statistics.

\subsection{Uncertainty analysis}

The uncertainties of $\mathrm{Hg}$ emissions, including by different species, are quantified by sector and year using a Monte Carlo framework developed by Zhao et al. (2011). Probability distributions are estimated for all input parameters, and 10000 simulations are then performed to estimate the uncertainties of emissions and to identify the crucial parameters that significantly contribute to the uncertainties for different source types.

In most cases, the uncertainties of activity levels (including penetration rates of different technologies by sector) are determined following our previous work (Zhao et al., 2011, 2013). Generally, normal distributions are assumed for all the fuel consumption and industrial and agricultural production, with coefficients of variation $(\mathrm{CV}$, the standard deviation divided by the mean) set at 5,10 , and $20 \%$ for power, industry, and residential and commercial sectors, respectively. A comprehensive analysis of uncertainties of $\mathrm{Hg}$ emission factors was conducted by sector and species, with domestic field measurements thoroughly evaluated. For parameters with adequate measurement data, the Kolmogorov-Smirnov test for the goodness-of-fit ( $p=0.05)$ is applied and, if the test is passed, a bootstrap simulation is conducted to determine the probability distribution (Frey and Zheng, 2002; Zhao et al., 2010, 2011). For parameters that fail to pass the goodness-offit test or those with limited observational data, probability distributions must be assumed based on previous work (e.g., Wu et al., 2010) and/or the authors' judgments. Details about the emission factor uncertainties by sector will be discussed in Sect. 3.

For ASGM, in which emissions were not calculated but taken directly from Telmer and Veiga (2009) as described in Sect. 2.2, the uncertainties are assumed at $\pm 67 \%$ according to expert judgment (AMAP/UNEP, 2013). Muntean et al. (2014) compared the ASGM emissions estimated from varied methods and data sources (AGC, 2010; Telmer and Veiga, 2009), and the differences are within the uncertainty range assumed in this work.

\subsection{Emission projections to 2030}

Three scenarios are devised to project China's atmospheric $\mathrm{Hg}$ emissions in 2015, 2020, and 2030. Scenario 0 (S0) is the most conservative case, in which the national policy of energy saving and air pollution control will not change in practice after 2012. This does not imply, however, that the penetration levels of advanced technologies and emission control devices in specific sectors will necessarily be the same as in 2012. For example, current policies for the power sector will undoubtedly raise the use of FGD and SCR systems, and that for cement will increase the share of precalciner kilns with FF systems (i.e., this share would reach $100 \%$ in 2030, compared to $88 \%$ in 2012). While keeping the control strategy the same as in S0, Scenario 1 (S1) integrates the national energy policy commitments that have been announced (e.g., the plans to reduce fossil energy use and to reduce greenhouse gas emissions) and thus illustrates the benefits of enhanced energy saving on $\mathrm{Hg}$ emissions. The activity-level data for S0 and S1 are taken respectively from the Current Policy Scenario (CPS) and New Policy Scenario (NPS) of our previous work (Zhao et al., 2014), which are based mainly on projections by IEA (2012), with revisions in specific sectors including power and transportation. For sources that are not mentioned in Zhao et al. (2014), specific working reports are consulted. For example, the burned ratio of urban municipal solid waste is assumed to reach $50 \%$ in 2030, according to CAUES (2013). Scenario 2 (S2) shares the same activity level trends as $\mathrm{S} 1$ but includes more stringent emission controls, mainly for industrial sources. Those measures include use of advanced control devices specifically for $\mathrm{Hg}$ removal in new power plants, use of FGD systems in new industrial and heating boilers, use of SCR in new cement precalciner kilns starting in 2020, greater penetration of electric furnaces in steel smelting (resulting in less pig-iron production and thereby less coal combustion), and greater penetration of advanced manufacturing technologies, with lower $\mathrm{Hg}$ emission factors, in nonferrous metal smelting. The detailed control benefits of those technologies on $\mathrm{Hg}$ emissions are described in the next section.

\section{Evolution of emission factors}

\subsection{Evolution of emission factors for key sectors, including key assumptions and uncertainties}

The improvement of emission factors result mainly from two sources: (1) new and better data through domestic measurements for key sectors; and (2) better understanding of penetration levels of manufacturing and control technologies for different sources during 2005-2012. Those improvements 


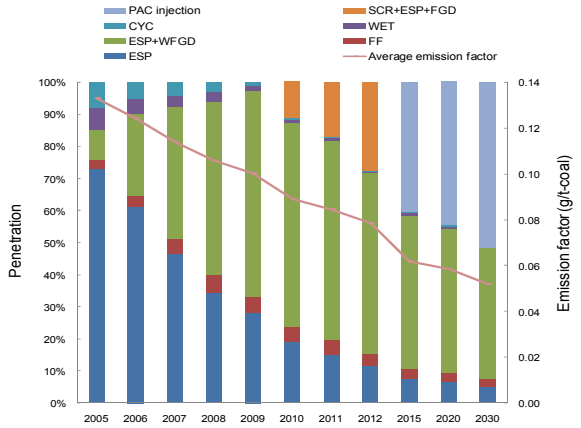

(a) Coal-fired power plants

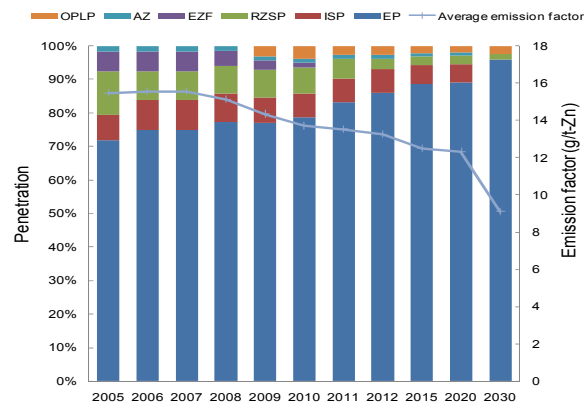

(d) Zn smelting

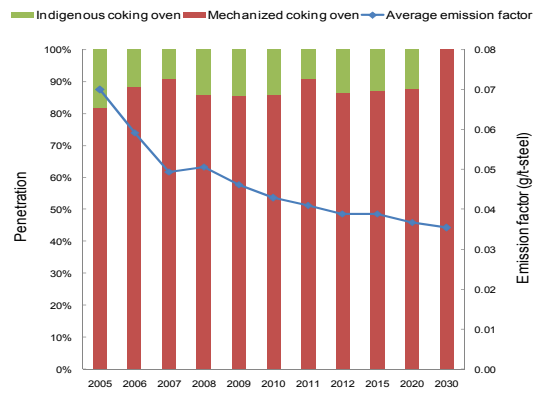

(b) Iron \& steel production

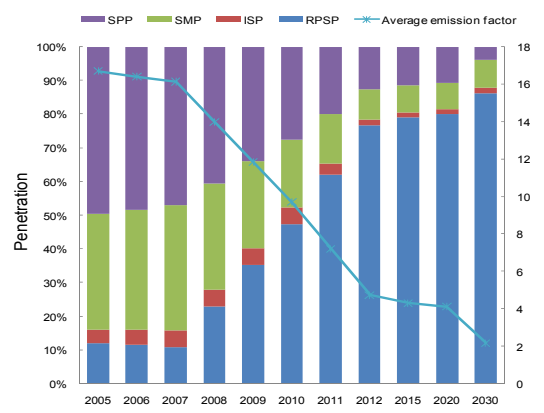

(e) $\mathrm{Pb}$ smelting

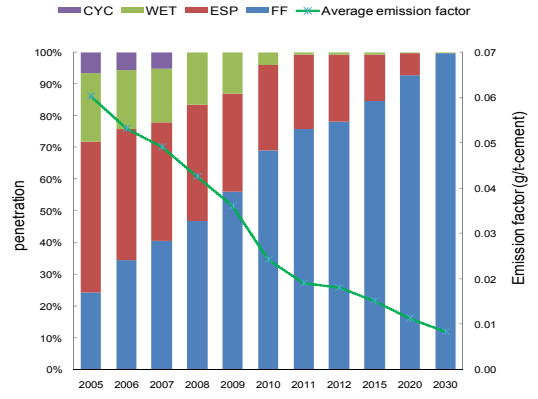

(c) Cement production

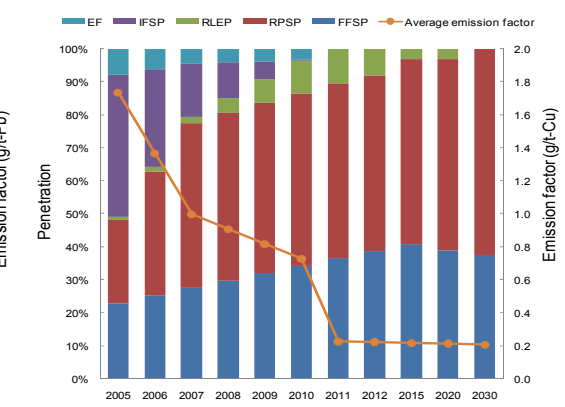

(f) Cu smelting

Figure 1. The penetrations of technologies and inter-annual trends of Hg emission factors for typical sources in China for 2005-2012 and S2 through 2030. In each panel, the left vertical axis indicates the percentages of various technologies and the right vertical axis indicates the emission factors.

provide more accurate emission factors, with clearer interannual trends by sector, as shown in Fig. 1. Through comprehensive review of the literature, a database for $\mathrm{Hg}$ emission factors (and related parameters) by sector is established for China, with the uncertainty for each emission factor or parameter analyzed and presented as a probability distribution function (PDF), as summarized in Table 1.

\subsubsection{Power plants}

As Eq. (3) indicates, the integrated $\mathrm{Hg}$ emission factor for power plants, expressed in metric tons $(\mathrm{t})$ of $\mathrm{Hg}$ emissions per million metric tons (Mt) coal combusted, is calculated as the product of the $\mathrm{Hg}$ content of coal, the release rate of the specific combustion facility, and the difference of one and the $\mathrm{Hg}$ removal efficiency of a specific air pollution control device (APCD).

The $\mathrm{Hg}$ content of coal in China has been addressed in a series of studies (Wang et al., 2000; Huang and Yang, 2002; Feng et al., 2002; USGS (unpublished data), 2004; Zheng et al., 2007; Zhang et al., 2012a), and the method of Wu et al. (2010) is followed in the current work to determine the values and uncertainties by province. The percentages of $\mathrm{Hg}$ content by province are estimated based on available measurement data and a conservative assumption of a lognormal distribution is applied as the PDF, with relatively long tails for the distributions in most provinces. Regarding the release rates, the values for pulverized combustion (PC), circulating fluidized bed (CFB), and grate boiler systems reach 98.7, 98.4, and $95.9 \%$, respectively, reflecting that most $\mathrm{Hg}$ in coal is emitted into the flue gas due to the high combustion temperature (see details in Table S1 in the Supplement). As currently available measurements are insufficient for data fitting to determine the uncertainties, triangular distributions are assumed for the parameter, with the lowest and highest measurement values taken as the 10th and 90th percentiles of each distribution, respectively.

Deployment of advanced APCDs in the coal-fired power sector has increased since 2005. The penetration levels of FGD and SCR systems, for example, reached 90 and $27 \%$, respectively, in 2012. These technologies demonstrably result in lower $\mathrm{Hg}$ emission factors and thereby ancillary benefits in Hg removal (Wang et al., 2012). The removal efficiencies of major types of APCDs, including ESP, FF, joint ESP and FGD (ESP + FGD), and joint SCR, ESP, and FGD (SCR + ESP + FGD), are analyzed using the most recent field measurements at China's power plants (see details in Table S2 in the Supplement). As shown in Fig. 2, $\mathrm{SCR}+\mathrm{ESP}+\mathrm{FGD}$ systems have the highest $\mathrm{Hg}$ removal efficiency, at $76.6 \%$, followed by FF at $56.1 \%$ and ESP + FGD at $53.8 \%$. Large variations of $\mathrm{Hg}$ removal efficiencies of APCDs are indicated by different studies, and the values es- 
Table 1. Uncertainties of $\mathrm{Hg}$ emission factors for main sources, expressed as the probability distribution functions (PDF).

\begin{tabular}{|c|c|c|c|c|c|c|}
\hline \multirow[t]{2}{*}{ Parameters } & & \multirow[t]{2}{*}{ Samples } & \multirow[t]{2}{*}{ Distribution $^{\mathrm{a}}$} & \multicolumn{3}{|c|}{ Key characteristics for distribution functions } \\
\hline & & & & $\mathrm{P} 10^{\mathrm{b}} / \mathrm{Min}^{\mathrm{c}}$ & $\mathrm{P} 90^{\mathrm{b}} / \mathrm{Max}^{\mathrm{c}}$ & Mean $^{\mathrm{b}} /$ Most likely ${ }^{\mathrm{c}}$ \\
\hline \multicolumn{7}{|c|}{ Release rates of boilers for CPP, $\%$} \\
\hline PC & & 32 & Triangular & 89 & 100 & 99 \\
\hline Grate & & 2 & Triangular & 92 & 100 & 96 \\
\hline CFB & & 3 & Triangular & 93 & 100 & 98 \\
\hline \multicolumn{7}{|c|}{ Release rates of boilers for OIB/HB/FOS, $\%$} \\
\hline Grate & & 3 & Triangular & 51 & 91 & 76 \\
\hline CFB & & 1 & Triangular & 51 & 100 & 91 \\
\hline \multicolumn{7}{|c|}{ Hg removal efficiency by APCDs for CPP, $\%$} \\
\hline $\mathrm{FF}$ & & 5 & Weibull & 21 & 84 & 56 \\
\hline ESP & & 44 & Normal & 18 & 23 & 20 \\
\hline WET & & 3 & Weibull & 4 & 26 & 13 \\
\hline $\mathrm{FGD}+\mathrm{ESP}$ & & 30 & Weibull & 40 & 68 & 57 \\
\hline CYC & & 3 & Uniform & 0 & 14 & - \\
\hline SCR & & 7 & Triangular & 10 & 100 & 77 \\
\hline $\mathrm{CFB}+\mathrm{ESP}$ & & 3 & Weibull & 18 & 60 & 43 \\
\hline \multicolumn{7}{|c|}{ Nonferrous metal smelting ${ }^{d}$} \\
\hline \multirow{4}{*}{ Zinc } & $\mathrm{EP}$ & 6 & Triangular & 0 & 45 & 9 \\
\hline & ISP & 3 & Uniform & 0 & 140 & - \\
\hline & RZSP & 2 & Uniform & 2 & 38 & - \\
\hline & AZSP & 4 & Triangular & 4 & 203 & 89 \\
\hline \multirow{2}{*}{ Lead } & RPSP & 2 & Uniform & 0 & 1.4 & - \\
\hline & SMP & 2 & Uniform & 0 & 12 & - \\
\hline \multirow{2}{*}{ Copper } & FFSP & 2 & Uniform & 0 & 0.3 & - \\
\hline & RPSP & 2 & Uniform & 0.1 & 0.3 & - \\
\hline \multicolumn{7}{|c|}{ Cement production } \\
\hline FF & & 7 & Weibull & 0.006 & 0.011 & 0.008 \\
\hline ESP & & 2 & Uniform & 0.01 & 0.11 & - \\
\hline WET/CYC & & 2 & Uniform & 0.06 & 0.18 & - \\
\hline \multicolumn{7}{|c|}{ Biofuel use/biomass open burning } \\
\hline Firewood & & 26 & Uniform & 0 & 50 & - \\
\hline Crops & & 9 & Uniform & 0 & 106 & - \\
\hline \multicolumn{7}{|c|}{ Waste incineration } \\
\hline Municipal & & 29 & Weibull & 0.21 & 0.32 & 0.27 \\
\hline \multirow{2}{*}{ Rural } & Release rates & 1 & Normal & 0.37 & 0.63 & 0.5 \\
\hline & $\mathrm{Hg}$ content & 31 & Weibull & 0.12 & 1.58 & 0.6 \\
\hline
\end{tabular}

a Types of probability distributions: Triangular distribution: a continuous probability distribution based on a knowledge of the minimum and maximum and an "inspired guess" as to the modal value; Weibull distribution: a continuous probability distribution described by equation $f(x)=\frac{\beta}{\eta}\left(\frac{x-\gamma}{\eta}\right)^{\beta-1} e^{-\left(\frac{x-\gamma}{\eta}\right)^{\beta}} ;$ normal distribution: a continuous probability distribution described by the normal equation $f(x)=\frac{1}{\sigma \sqrt{2 \pi}} e^{-\frac{(x-\mu)^{2}}{2 \sigma^{2}}} ;$ uniform distribution: a distribution that has constant probability within the given range. ${ }^{\mathrm{b}} \mathrm{P} 10$ values mean that there is a probability of $10 \%$ that the actual result would be equal to or below the P10 values; P50 mean that there is a probability of $50 \%$ that the actual result would be equal to or below the P50 values; and P90 mean that there is a probability of $90 \%$ that the actual result would be equal to or below the P90 values. ${ }^{\mathrm{c}}$ These values are for the minimum, the most likely, and the maximum values for the triangular distribution function instead of P10, P50, and P90 values, or for the minimum and maximum values for the uniform distribution function instead of P10 and P90

values. ${ }^{\mathrm{d}}$ Full names of manufacturing technologies: EP: electrolytic process; ISP: imperial smelting process; RZSP: retort zinc smelting process; AZ: artisanal zinc smelting process; RPSP: rich-oxygen pool smelting process; SMP: sinter machine process; and FFSP: flash furnace smelting process. 


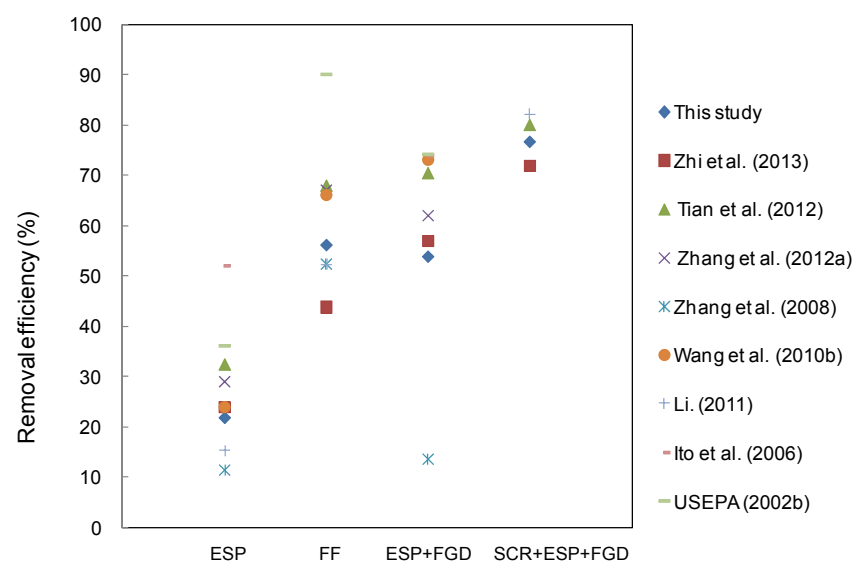

Figure 2. Mercury removal efficiencies of different APCD combinations estimated in this work, compared with other inventory studies.

timated and applied in this work are relatively conservative, particularly for ESP + FGD, which is currently the dominant APCD configuration in China's power sector. In addition, the removal efficiencies are much lower than those in developed countries like the US and Japan. Two reasons could be a large difference in coal qualities between the countries and the poorer operational conditions of APCDs in China ( $\mathrm{Li}$, 2011; Zhi et al., 2013). For other dust collectors including wet scrubbers (WET) and cyclones (CYC), limited domestic information from field tests (e.g., Huang et al., 2004) leads to higher removal efficiencies than previous inventories (Streets et al., 2005; Wu et al., 2006). We believe these values do not significantly raise the uncertainty because the capacity share of units with either WET or CYC is small, i.e., roughly $2 \%$ in 2010 .

Regarding the prospects for further improvement of $\mathrm{Hg}$ emission control in the future, newly-built power units are assumed to apply powdered activated carbon (PAC) injection technology (Srivastava et al., 2006; Cui et al., 2011) or modified catalytic oxidation of elemental $\mathrm{Hg}$ (Guo et al., 2011; Yan et al., 2011) in S2, and the average Hg removal efficiencies of those technologies are expected to reach $90 \%$. The PDFs of removal efficiencies by device are estimated following the description in Sect. 2.3. In most cases, the PDFs are assumed to be Weibull distributions due to insufficient data samples. For ESP, however, the data from currently available measurements pass the statistical test, and bootstrap simulation is thus conducted to determine a normal PDF, as shown in Fig. S1a in the Supplement.

Due mainly to the sharply growing use of APCDs, the average $\mathrm{Hg}$ emission factor for power plants is estimated to have decreased from $0.13 \mathrm{~g} \mathrm{t}^{-1}$ coal in 2005 to 0.08 in 2012, as shown in Fig. 1a. With PAC injection applied in the future under S2, the average emission factor would further decline to $0.05 \mathrm{~g} \mathrm{t}^{-1}$ coal in 2030 .

\subsubsection{Iron and steel production}

In previous studies, a uniform emission factor of $0.04 \mathrm{~g} \mathrm{t}^{-1}$ steel has generally been applied for iron and steel production, with little consideration of improving production technologies (Streets et al., 2005; Wu et al., 2006). In this work, as described in Sect. 2.2, the latest information on APCD penetration trends and removal efficiencies is combined, $\mathrm{Hg}$ emissions are calculated separately for each coal-consuming process using Eq. (3), and these are then aggregated to the sector level. The Hg release ratios of coking and pig-iron production are estimated at 63 and $84 \%$, respectively (Wang et al., 2000; Hong et al., 2004), with uniform distributions conservatively assumed due to a lack of updated measurements. Without specific further information, the removal efficiencies and PDFs for the iron and steel industry are assumed to be the same as those for the power sector. This assumption is expected to result in a possible underestimate of emissions for the sector, because the APCD operations may not be as thorough as those at power plants, given the greater regulatory oversight of the latter in recent years. Although this possible underestimate could be partly quantified by uncertainty analysis, more investigation of the APCD benefits on $\mathrm{Hg}$ removal for the iron and steel sector is needed first (as is also the case with other non-power industrial sectors).

Driven by the increased penetration of advanced manufacturing and emission control technologies, in particular the growth of mechanized coking ovens, the emission factor for iron and steel production is estimated to have declined from 0.071 to $0.039 \mathrm{~g} \mathrm{t}^{-1}$ steel from 2005 to 2012 , indicating that the application of $0.04 \mathrm{~g} \mathrm{t}^{-1}$ steel in earlier studies might have underestimated the emissions for this sector in previous years (Fig. 1b). Regarding the future projection, the ratio of pig iron to steel is assumed to decrease from $92 \%$ in 2012 to $80 \%$ in 2030 in S2, due to expanding use of electric arc furnaces that use more waste-steel inputs instead of more energy-intensive inputs including pig iron (Wang et al., 2007; Zhao et al., 2012). The emission factor would thus decline further to $0.035 \mathrm{~g} \mathrm{t}^{-1}$ steel.

\subsubsection{Non-ferrous metal smelting}

Although the non-ferrous metal industry, including smelting of $\mathrm{Pb}, \mathrm{Zn}$, and $\mathrm{Cu}$, is one of the main sources of $\mathrm{Hg}$ emissions (Li et al., 2010; Wu et al., 2012), available emission factors from field tests are still limited, given the many and complex factors that determine emission levels (e.g., the $\mathrm{Hg}$ concentration in ore concentrate, smelting technology, and the penetration of acid plants and APCDs). Due to these limited data, a process-based methodology is developed to estimate the emission factors for various kinds of smelters employed in China, as shown in Table S3 in the Supplement. Information on all of the processes and their corresponding emission factors are obtained from direct field measurements (Feng et al., 2004; G. Li et al., 2009, 2010; Wang et al., 2010a; 
Zhang et al., 2012b) or field-based calculations (Wu et al., 2012). Given the very small sample sizes, uniform distributions have to be assumed for most processes, with the lowest and highest measurement values subjectively taken as the 10th and 90th percentiles of each distribution, respectively. This conservative assumption provides relatively large variation of emission factors, indicating big uncertainties for them due to insufficient domestic field measurements. Notably, the oxygen-pressure leaching process for zinc smelting has not been included in the table, because it does not include the process of high-temperature calcination, and thus little mercury is released to the atmosphere.

Based on a plant-by-plant database (Wu et al., 2012) and a list of small smelters that have been shut down since 2010, the penetrations of various kinds of smelters are calculated by year and non-ferrous metal type, and the inter-annual trends of emission factors are then analyzed. As shown in Fig. 1d-f, the national average $\mathrm{EFs}$ for $\mathrm{Zn}, \mathrm{Pb}$, and $\mathrm{Cu}$ smelting are estimated to have dropped from $15.5,16.7$, and $1.7 \mathrm{~g} \mathrm{t}^{-1}$ product in 2005 to $13.3,4.7$, and $0.2 \mathrm{~g} \mathrm{t}^{-1}$ in 2012 , respectively. In the future projection of S2, the EFs are projected based on the assumption that the most advanced technologies will be required at all new smelters. The $\mathrm{EFs}$ for $\mathrm{Zn}$ and $\mathrm{Pb}$ are thus estimated to decline further to 9.1 and $2.2 \mathrm{~g} \mathrm{t}^{-1}$ product in 2030, respectively.

\subsubsection{Cement production}

A series of studies have been conducted to measure the $\mathrm{Hg}$ emission levels of cement production (Li, 2011; Zhang, 2007). Based on the available data from those field tests, the emission factors are estimated at $0.008,0.052$, and $0.120 \mathrm{~g} \mathrm{t}^{-1}$ product for cement kilns with FF, ESP, and WET dust collectors, respectively. The data sample for FF passes the statistical test and bootstrap simulation is applied to determine its PDF as a Weibull distribution, as shown in Fig. S1b in the Supplement. For other dust collectors, however, the current data are too limited and uniform distributions are used, with the lowest and highest measurement values taken as the 10th and 90th percentiles of each distribution, respectively.

Combining the inter-annual trends of APCD penetration for the sector (Lei et al., 2011; Zhao et al., 2013), the national average emission factor is estimated to have declined from 0.06 in 2005 to $0.018 \mathrm{~g} \mathrm{t}^{-1}$ in 2012 (Fig. 1c), resulting mainly from the increased use of precalciner kilns with FF. For the future, all kilns other than precalciners are expected to be closed by 2020 in S1 and S2, and by 2030 in S0. In addition, SCR systems are assumed to be deployed at all precalciner kilns in S2 (Zhao et al., 2014). These improvements would lead to reductions in the sector-average EFs to $0.013,0.012$, and $0.008 \mathrm{~g} \mathrm{t}^{-1}$ product in $\mathrm{S} 0, \mathrm{~S} 1$, and $\mathrm{S} 2$, respectively, in 2030. Regarding the emissions from coal combustion in cement production, the $\mathrm{Hg}$ removal efficiencies for various APCDs are applied to generate the emission factors, and the national average value is estimated to have declined from 0.11 to $0.08 \mathrm{~g} \mathrm{t}^{-1}$ coal during 2005-2012. While no significant abatement is found for S0 and S1 after 2010, the emission factor would further decrease to $0.04 \mathrm{~g} \mathrm{t}^{-1}$ coal in S2 by 2030, attributed to the greater use of SCR in the scenario.

\subsubsection{Other industrial sources}

The emission factors of industrial and heating boilers are estimated using Eq. (3). The $\mathrm{Hg}$ release ratios for grate boilers and CFB are estimated at 76 and $91 \%$ based on limited domestic measurements (Wang et al., 2000; Tang et al., 2004), and are lower than those of power plants. Uniform distributions are assumed to quantify the uncertainty of the parameter. WET and CYC are the dominant types of dust collectors for boilers and their removal efficiencies with PDF are assumed to be the same as those for power plants. For the future under S2, FGD is assumed to be deployed at all new boilers, leading to a larger fraction of $\mathrm{Hg}$ removal.

Production of polyvinyl chloride polymer (PVC) is a significant contributor to $\mathrm{Hg}$ emissions due to wide use of mercuric chloride catalyst in acetylene-making processes. The emission factor is calculated as the product of the $\mathrm{Hg}$ content in PVC and its atmospheric release ratio during the production process. The $\mathrm{Hg}$ content in $\mathrm{PVC}$ and the release ratio are estimated to range from 0.12 to $0.20 \mathrm{~kg} \mathrm{Hg} \mathrm{t}^{-1} \mathrm{PVC}$ and to be $1 \%$, respectivly (Pirrone et al., 2010). For other processes including $\mathrm{Hg}$ mining, production of batteries and fluorescent lamps, large-scale gold production, and oil and gas combustion, the emission factors from AP-42 (USEPA, 2002a) and previous inventory work (Streets et al., 2005) are used due to a lack of updated information from domestic measurements. Given the big uncertainties for those emission factors, lognormal distributions are assumed for them with the CV conservatively set at $100 \%$, as suggested by Bond et al. (2004).

\subsubsection{Residential sources}

For residential coal consumption, the determination of $\mathrm{Hg}$ emission factors is similar to that of industrial boilers. Biomass combustion takes account of crop residues (used as biofuel in households and as waste burned in open fields) and fuel wood (used in households). Domestic information and field measurements are adopted from Huang et al. (2011) and Zhang et al. (2013) to estimate the emission factors, and uniform distributions are assumed, reflecting the relatively high uncertainty. Based on the domestic data set, the average EFs for combustion of crop residues ( $16.7 \mathrm{ng} \mathrm{g}^{-1}$ ) and fuel wood $\left(12.3 \mathrm{ng} \mathrm{g}^{-1}\right)$ calculated in this work are lower than the values adopted in previous literature (e.g., $37 \mathrm{ng} \mathrm{g}^{-1}$ for crop residues and $20 \mathrm{ng} \mathrm{g}^{-1}$ for fuel wood, Streets et al., 2005).

$\mathrm{Hg}$ emissions from solid waste incineration (SWI) are estimated separately for municipal solid waste incineration (MSWI) and rural household waste incineration (RHWI), 
due to different mercury content levels and burning techniques. For MSWI, an emission factor of $0.22 \mathrm{~g} \mathrm{t}^{-1}$ with Weibull distribution is estimated, with bootstrap simulation based on domestic field tests by $\mathrm{L}$. Chen et al. (2013) and $\mathrm{Hu}$ et al. (2012) (Fig. S1c in the Supplement). The emission factor for RHWI is estimated as the product of $\mathrm{Hg}$ content and the atmospheric release ratio, which are obtained from $\mathrm{Hu}$ et al. (2012).

\subsection{Speciation of $\mathbf{H g}$ with probability distribution functions}

The speciation of $\mathrm{Hg}$ plays a crucial role in its atmospheric fate and transport, and chemical cycling. The fate of $\mathrm{Hg}$ released to atmosphere varies by species $\left(\mathrm{Hg}^{0}, \mathrm{Hg}^{2+}\right.$, and $\mathrm{Hg}^{\mathrm{p}}$ ), which in turn are determined by fuel quality and the removal mechanisms of APCDs, thereby varying significantly by emission source. A thorough review of existing studies is conducted to compile a database of $\mathrm{Hg}$ speciation by sector, and to provide the mass fractions of the three main chemical forms (see details in Table S4 in the Supplement). In general, the emission sources that determine $\mathrm{Hg}$ speciation can be divided into three categories, according to the nature of APCD deployment and data availability. First are those sources whose emission factors can be calculated based on the removal efficiencies of different APCD (e.g., CPP, CEM, ISP, OIB and RC), in which case the mass fractions are estimated based on results from field measurements by type of APCD. Second are sources with insufficient measurement samples to determine emission factors by APCD, in which case the average values of available field test results are calculated and directly applied as the mass fractions of the three species for the sector (e.g., NMS, BIO and SWI). Third are sources for which very little domestic information about speciation can be found, in which case results from global studies (Pacyna and Pacyna, 2002) have to be used, with little update to previous inventories (Streets et al., 2005). Those sources mainly include industrial processes like artisanal gold production, $\mathrm{Hg}$ mining, and battery and fluorescent lamp production.

As shown in Table $\mathrm{S} 4$, the speciation of total $\mathrm{Hg}$ varies considerably by different types of APCD configurations. For example, the $\mathrm{Hg}^{0}$ mass fraction averaged over all estimates in the literature is $83 \%$ for ESP + FGD, attributed to the relatively strong removal effects of both ESP and FGD on $\mathrm{Hg}^{2+}$ and $\mathrm{Hg}^{\mathrm{p}}$. Inclusion of SCR leads to significant increase in the $\mathrm{Hg}^{2+}$ fraction, resulting mainly from the conversion of $\mathrm{Hg}^{0}$ to $\mathrm{Hg}^{2+}$ by the SCR process (Wang et al., 2010b). In general, oxidation of $\mathrm{Hg}^{0}$ leads to higher removal of $\mathrm{Hg}$ because $\mathrm{Hg}^{2+}$ is more liable to be adsorbed in FGD scrubber solution, and use of advanced dust collectors leads to lower $\mathrm{Hg}^{\mathrm{p}}$ as most of it can be captured on particles.

For mass fraction data that pass the Kolmogorov-Smirnov test, bootstrap simulation is applied to determine a PDF, e.g., the mass fractions of $\mathrm{Hg}^{2+}$ for ESP, ESP + FGD and

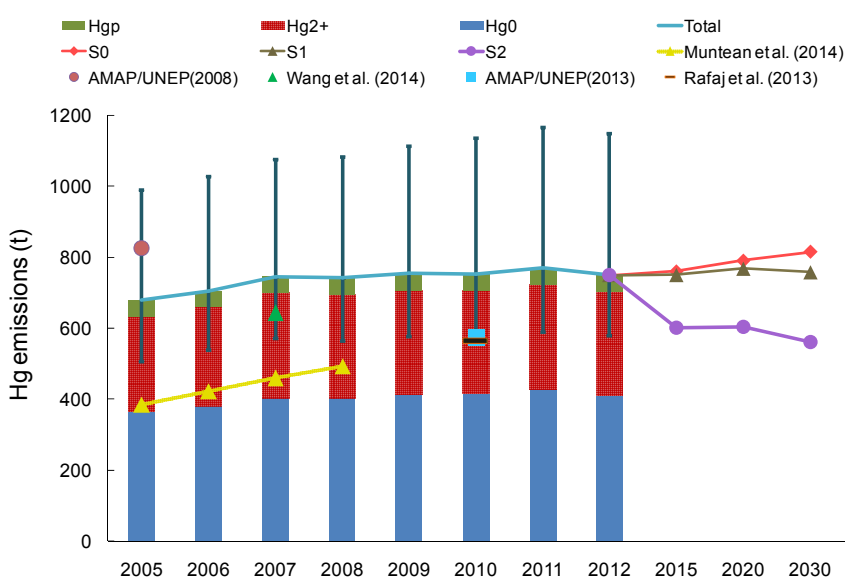

Figure 3. National total $\mathrm{Hg}$ emissions with speciation from 2005 to 2012 and future trends under three scenarios through 2030. The error bars for 2005-2012 indicate the $95 \%$ confidence intervals of the annual total emission estimates. Estimates from other inventories are shown as well for comparison.

SCR + ESP + FGD (Fig. S1d-f in the Supplement). Otherwise, triangular or uniform distributions are applied. The PDFs for $\mathrm{Hg}$ speciation are summarized in Table 2.

\section{Results and discussion}

\subsection{Historical trends in mercury emissions to the atmosphere}

The total national emissions of anthropogenic $\mathrm{Hg}$ are estimated to have increased from $679.0 \mathrm{t}$ in 2005 to $749.8 \mathrm{t}$ in 2012, with a peak of $770.6 \mathrm{t}$ in 2011, as shown in Fig. 3. The annual growth rate of emissions averaged $1.4 \%$ during 2005-2012, much lower than that of China's energy consumption $(7.6 \%)$ or the economy (>10\%). The result reflects effective constraints on $\mathrm{Hg}$ emissions since 2005, compared to relatively fast growth in early 2000 s (e.g., $8 \%$ annual growth of $\mathrm{Hg}$ emissions from 2000 to 2003 suggested by Wu et al., 2006). This national trend, however, is currently difficult to confirm fully with field observations, given the lack of long-term monitoring data for atmospheric ambient $\mathrm{Hg}$ in either polluted cities or background regions. Limited inter-annual results for one background area (Changbai Mountain in northeastern China) show reduced Hg levels (Wan et al., 2009; Fu et al., 2012b), but those differences are believed to result from changes in sampling location rather than emissions (personal communication with $\mathrm{X}$. Fu of the Institute of Geochemistry, Chinese Academy of Sciences, 2014). For speciation of $\mathrm{Hg}$ emissions, clear changes are found for different sectors. For example, the fraction of $\mathrm{Hg}^{0}$ to total $\mathrm{Hg}$ for power generation is estimated to increase from 59 to $75 \%$ during 2005-2012, due to increased use of FGD systems; while that for cement and iron and steel produc- 
Table 2. Uncertainties of mass fractions of $\mathrm{Hg}$ speciation for main source categories.

\begin{tabular}{|c|c|c|c|c|c|c|}
\hline \multirow[t]{2}{*}{ Parameters } & & \multirow[t]{2}{*}{ Samples } & \multirow[t]{2}{*}{ Distribution } & \multicolumn{3}{|c|}{ Key characteristics for distribution functions / $\%$} \\
\hline & & & & P10/Min & P90/Max & Mean/Most likely \\
\hline \multirow{2}{*}{$\mathrm{FF}$} & $\mathrm{Hg}^{0}$ & 4 & Triangular & 4.8 & 30.6 & 15.8 \\
\hline & $\mathrm{Hg} \mathrm{p}$ & 4 & Triangular & 0.0 & 34.8 & 10.8 \\
\hline \multirow{2}{*}{ ESP } & $\mathrm{Hg}^{2+}$ & 20 & Normal & 27.9 & 42.4 & 35.2 \\
\hline & $\mathrm{Hg}^{\mathrm{p}}$ & 20 & Triangular & 0.0 & 3.6 & 0.22 \\
\hline \multirow{2}{*}{$\mathrm{FGD}+\mathrm{ESP}$} & $\mathrm{Hg}^{2+}$ & 11 & Normal & 9.8 & 22.2 & 16.0 \\
\hline & $\mathrm{Hg}^{\mathrm{p}}$ & 11 & Triangular & 0.0 & 3.7 & 0.3 \\
\hline \multirow{2}{*}{ WET } & $\mathrm{Hg}^{0}$ & 2 & Uniform ${ }^{b}$ & 0.0 & 60.0 & - \\
\hline & $\mathrm{Hg}^{\mathrm{p}}$ & 2 & Uniform $^{b}$ & 0.0 & 28.0 & - \\
\hline \multirow{2}{*}{$\mathrm{NOC}^{\mathrm{a}}$} & $\mathrm{Hg}^{0}$ & - & Uniform ${ }^{b}$ & 0.0 & 48.0 & - \\
\hline & $\mathrm{Hg}^{2+}$ & - & Uniform $^{b}$ & 0.0 & 40.0 & - \\
\hline SCR & $\mathrm{Hg}^{2+}$ & 6 & Triangular & 15.7 & 40.6 & 27.6 \\
\hline \multirow{2}{*}{ NMS_Zn } & $\mathrm{Hg}^{0}$ & 3 & Triangular & 0.0 & 55.0 & 29.0 \\
\hline & $\mathrm{Hg}^{\mathrm{p}}$ & 3 & Uniform & 0.0 & 5.0 & - \\
\hline NMS_Pb & $\mathrm{Hg}^{2+}$ & 2 & Triangular & 15.0 & 65.0 & 40.0 \\
\hline NMS_Cu & $\mathrm{Hg}^{2+}$ & 2 & Uniform & 28.0 & 72.0 & - \\
\hline \multirow{2}{*}{ BIO } & $\mathrm{Hg}^{0}$ & 25 & Weibull & 57.3 & 94.2 & 76.9 \\
\hline & $\mathrm{Hg}^{2+}$ & 25 & Triangular & 0.0 & 21.7 & 5.0 \\
\hline \multirow{2}{*}{ SWI } & $\mathrm{Hg}^{0}$ & 10 & Gamma & 1.1 & 33.8 & 6.2 \\
\hline & $\mathrm{Hg}^{\mathrm{p}}$ & 10 & Gamma & 0.1 & 2.6 & 0.5 \\
\hline
\end{tabular}

${ }^{\mathrm{a}}$ No control device for coal combustion; ${ }^{\mathrm{b}}$ tentatively assumed.

tion decrease from 44 to $33 \%$ and 43 to $30 \%$, respectively, due to increased use of fabric filters. The varied speciation of emissions from different sectors compensates each other, leading to relatively stable speciation of total anthropogenic $\mathrm{Hg}$ emissions for recent years (around 55, 39, and 6\% for $\mathrm{Hg}^{0}, \mathrm{Hg}^{2+}$, and $\mathrm{Hg}^{\mathrm{p}}$, respectively).

The annual emissions by source category are summarized in Table 3. Coal combustion, gold mining, and nonferrous metal smelting are the largest sources of anthropogenic $\mathrm{Hg}$, accounting together for $85 \%$ of national total emissions. The share of coal combustion (from the power sector, industrial and heating boilers, cement kilns, residential stoves, and iron and steel production, in declining order) to total national emissions is estimated to have increased from $43 \%$ in 2005 to $49 \%$ in 2012 . This is mainly due to relatively constant emission levels of gold mining and nonferrous metal sectors during the same period, resulting from penetration of newer and more advanced mining and manufacturing technologies. Emissions of $\mathrm{Hg}^{0}, \mathrm{Hg}^{2+}$ and $\mathrm{Hg}^{\mathrm{p}}$ are summarized by sector in Table S5-S7 of the Supplement. For $\mathrm{Hg}^{0}$ and $\mathrm{Hg}^{2+}$, the three biggest sources are the same as those for total $\mathrm{Hg}$ emissions, i.e., coal combustion, gold mining, and nonferrous metal smelting. For $\mathrm{Hg}^{\mathrm{p}}$, coal combustion plays a domi- nant role, with the share ranging from 78 to $84 \%$ for various years, as very few $\mathrm{Hg}^{\mathrm{p}}$ emissions are estimated from gold mining, zinc smelting, and lead smelting.

Provincial emissions, including inter-annual variations, are assessed and illustrated in Fig. 4. Because of uncertainties about both emission levels and spatial distribution, $\mathrm{Hg}$ emissions from ASGM are omitted from the provincial analysis. While coal combustion is identified as the biggest source of atmospheric $\mathrm{Hg}$ in most provinces, relatively high emissions from non-combustion sources are estimated for several provinces including Hunan, Yunnan, Henan, Guangxi, Anhui, and Shaanxi, resulting mainly from the large production of $\mathrm{Zn}$ and/or $\mathrm{Pb}$ in those regions. Clear differences in emission trends from 2005 to 2012 are found by region. In contrast to most provinces that have seen increasing emissions, the three regions with the highest densities of population, economic activity, and other pollution show declining estimated emissions, i.e., the Jing-Jin-Ji region (JJJ, including Beijing, Tianjin and Hebei), the Yangtze River Delta region (YRD, including Shanghai, Jiangsu and Zhejiang), and the Pearl River Delta region (PRD, including Guangdong). The collective share of total $\mathrm{Hg}$ emissions of the 7 provinces in these regions is estimated to have declined from $24 \%$ in 
Table 3. National Hg emissions by source category from 2005 to 2012.

\begin{tabular}{|c|c|c|c|c|c|c|c|c|}
\hline Source category & 2005 & 2006 & 2007 & 2008 & 2009 & 2010 & 2011 & 2012 \\
\hline Coal-fired power plants & 144.7 & 149.5 & 152.5 & 144.2 & 140.6 & 140.0 & 155.8 & 143.6 \\
\hline Industry & 473.0 & 495.9 & 530.0 & 533.8 & 546.0 & 542.3 & 540.3 & 526.4 \\
\hline Cement production & 64.4 & 65.8 & 66.8 & 59.1 & 59.4 & 45.7 & 40.1 & 40.0 \\
\hline Coal use & 16.1 & 17.6 & 18.7 & 18.0 & 20.0 & 20.4 & 21.5 & 22.2 \\
\hline Iron and steel plants & 26.2 & 28.0 & 28.2 & 29.7 & 32.3 & 34.8 & 36.8 & 37.6 \\
\hline Heating boilers & 18.1 & 20.5 & 24.1 & 26.0 & 26.3 & 30.1 & 32.6 & 34.5 \\
\hline Other industrial boilers & 61.2 & 66.7 & 76.0 & 81.6 & 83.7 & 80.6 & 87.9 & 87.4 \\
\hline Nonferrous metal smelting & 87.4 & 98.1 & 114.2 & 108.1 & 112.7 & 117.6 & 105.1 & 91.4 \\
\hline Zinc & 43.0 & 49.0 & 58.3 & 59.2 & 63.4 & 72.2 & 69.9 & 68.1 \\
\hline Lead & 39.9 & 45.0 & 52.4 & 45.6 & 45.8 & 41.9 & 34.0 & 22.0 \\
\hline Copper & 4.5 & 4.1 & 3.4 & 3.4 & 3.5 & 3.5 & 1.2 & 1.4 \\
\hline Gold mining & 184.4 & 183.8 & 183.8 & 182.3 & 183.3 & 179.5 & 181.0 & 182.6 \\
\hline Large scale & 17.7 & 17.1 & 17.1 & 15.6 & 16.6 & 12.8 & 14.3 & 15.9 \\
\hline Artisanal and small scale & 166.7 & 166.7 & 166.7 & 166.7 & 166.7 & 166.7 & 166.7 & 166.7 \\
\hline Other miscellaneous processes & 31.2 & 33.1 & 37.0 & 47.0 & 48.4 & 54.1 & 56.8 & 52.9 \\
\hline Mercury mining & 16.2 & 13.5 & 14.2 & 23.7 & 25.3 & 28.2 & 28.3 & 24.0 \\
\hline Battery/fluorescent lamp production & 7.6 & 8.7 & 9.8 & 10.9 & 10.0 & 10.0 & 10.0 & 10.0 \\
\hline PVC production & 7.0 & 8.8 & 10.7 & 10.0 & 10.7 & 13.6 & 16.0 & 16.3 \\
\hline Oil and gas combustion & 0.5 & 2.1 & 2.3 & 2.3 & 2.4 & 2.4 & 2.6 & 2.6 \\
\hline Residential and commercial sector & 61.3 & 59.8 & 61.4 & 63.6 & 67.8 & 70.7 & 74.2 & 79.5 \\
\hline Coal burning & 30.0 & 28.0 & 27.2 & 30.7 & 33.0 & 34.9 & 36.5 & 38.5 \\
\hline Biofuel use/biomass open burning & 10.3 & 10.5 & 9.7 & 9.2 & 9.4 & 8.2 & 8.3 & 8.4 \\
\hline Solid waste incineration & 10.3 & 10.9 & 11.4 & 11.6 & 12.4 & 12.8 & 13.3 & 15.3 \\
\hline Municipal & 1.7 & 2.5 & 3.2 & 3.5 & 4.4 & 5.1 & 5.7 & 7.9 \\
\hline Rural & 8.6 & 8.4 & 8.2 & 8.1 & 7.9 & 7.7 & 7.6 & 7.4 \\
\hline Oil and gas combustion & 10.7 & 10.4 & 13.1 & 12.1 & 13.0 & 14.9 & 16.1 & 17.4 \\
\hline Total & 679.0 & 705.2 & 743.8 & 741.7 & 754.4 & 753.0 & 770.3 & 749.5 \\
\hline Total coal combustion & 296.2 & 310.2 & 326.6 & 330.3 & 335.9 & 340.7 & 371.1 & 363.8 \\
\hline
\end{tabular}

2005 to $19 \%$ in 2012 , which is similar to trends in criteria air pollutants (Zhao et al., 2013). On one hand, this regional deviation indicates slower growth in heavily polluting industry and the progress of emission controls in highly developed regions. On the other hand, it indicates that China's air pollution challenges have been expanding to less developed interior provinces, which are experiencing rapid urbanization, accelerated economic development, and fast growth of pollution sources.

To be applicable to simulation of atmospheric transport and chemistry, annual $\mathrm{Hg}$ emissions at the provincial level are allocated to a $0.25^{\circ} \times 0.25^{\circ}$ grid system, applying the methods described in Zhao et al. (2012). Note that the emissions from production of coal-fired power, cement, and iron and steel are allocated at the unit or plant level (e.g., Fig. S2a in the Supplement for coal-fired power plants). Shown in Fig. S2b-d are the gridded emissions of China's anthropogenic $\mathrm{Hg}^{0}, \mathrm{Hg}^{2+}$ and $\mathrm{Hg}^{\mathrm{p}}$, respectively.

\subsection{Implication of emission controls on national $\mathrm{Hg}$ emissions}

China's anthropogenic $\mathrm{Hg}$ emissions have not increased as rapidly compared to the country's economic growth, reflecting the success of national strategies in broader emission control. While collectively causing this national trend, emission trends by sector have varied greatly due to different driving factors and uneven control policies. More detailed analysis is needed to disentangle the sources contributing most to the $\mathrm{Hg}$ emission trends. Particularly high uncertainty undermines estimation of emissions from ASGM, due to scarcity of input data and information, and its annual emission level is assumed unchanged over time in this work. Although recognized as the largest contributor of the individual sources to total $\mathrm{Hg}$ emissions (Table 3), ASGM must unfortunately be omitted here as a source type affecting the national emission trend due to these data constraints.

We divided the remaining anthropogenic sources into three categories, as indicated in Fig. 5a. The first category includes sources for which uniform and unchanged emission factors 


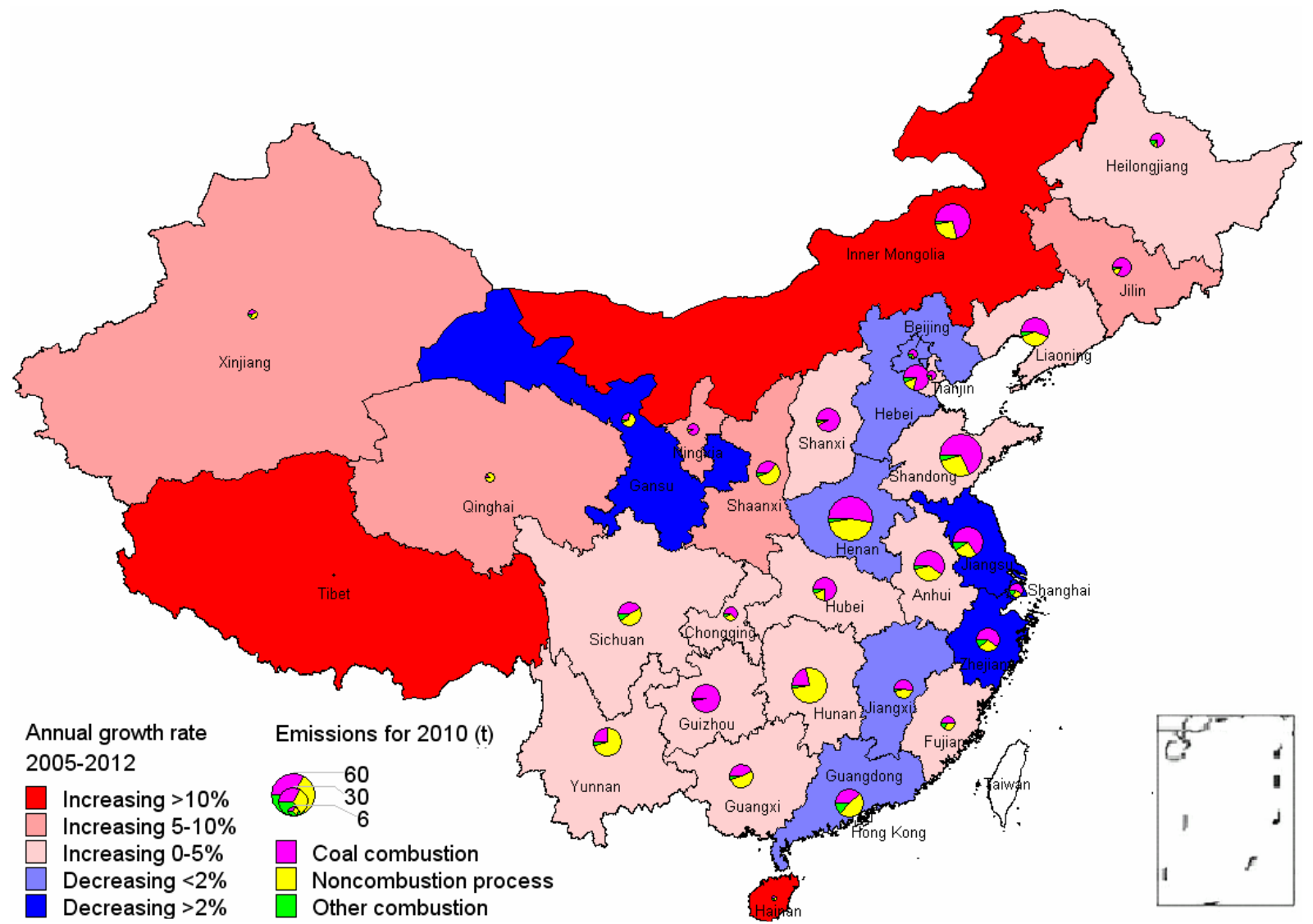

Figure 4. Provincial $\mathrm{Hg}$ emissions in 2010 and the relative changes between 2005 and 2012. The sizes of the pie graphs indicate absolute emissions by source in 2010. Emissions from ASGM are excluded.

are applied over time (i.e., LGM, BIO, SWI, and OMP). The inter-annual variability of $\mathrm{Hg}$ emissions from those sources are thereby only affected by the changes of activity levels, and the annual emissions for Category 1 sectors have continued to increase, from $80.3 \mathrm{t}$ in 2005 to $109.8 \mathrm{t}$ in 2012. Due to their relatively small fraction of total emissions $(<15 \%)$, however, the Category 1 sectors have little influence on the trend of the national total, which shows much slower growth and even reduced emissions in a few years, as shown in Fig. 5a. Category 2 consists of industrial fuel combustion (HB and OIB), and residential use (RC and ROG), those for which emission factors are region-dependent and show little inter-annual variation due to very limited implementation of pollution control measures. The $\mathrm{Hg}$ emission trend of these sources therefore depends mainly on the intensive coal use in recent years, and estimated emissions in 2012 are $47 \%$ higher than those of 2005. Category 3 includes CPP, CEM, ISP, and NMS. Although the activity levels (i.e., coal consumption and industrial production) increased in these sources at similar rates as the sectors of Categories 1 and 2, the $\mathrm{Hg}$ emission trends of Category 3 sectors are dominated by the combined effects of improved manufacturing technologies and increased use of APCDs to control criteria air pollutants. The emissions of these sectors are estimated to have peaked at $362 \mathrm{t}$ in 2007 , and then to have declined to $313 \mathrm{t}$ in 2012 , largely offsetting the increase in emissions from Categories 1 and 2 and playing a crucial role in constraining total national emissions.

Figure $5 \mathrm{~b}$ compares the trends of activity levels and $\mathrm{Hg}$ emissions for Category 3 sectors from 2005 to 2012. During the period, coal consumption from production of coalfired power, cement, steel, and nonferrous metals increased by $70,107,158$, and $104 \%$, respectively. A leveling of industrial production is found in 2008 , attributed to production constraints imposed for the Beijing Olympics and to the economic recession at the end of 2008. However, economic activities increased sharply again under a major economic stimulus policy responding to the recession, and energy and industrial production continued to grow swiftly in the following years. Despite the fast growth of activity levels, however, the $\mathrm{Hg}$ emissions from the four sectors were clearly constrained, to varying degrees: those from CEM decreased by $38 \%$, those from CPP and NMS in 2012 returned to the levels of 2005, and only those from ISP increased, by $44 \%$, though still far less than growth of steel production. As described in Sect. 3, the reduced emission factors 


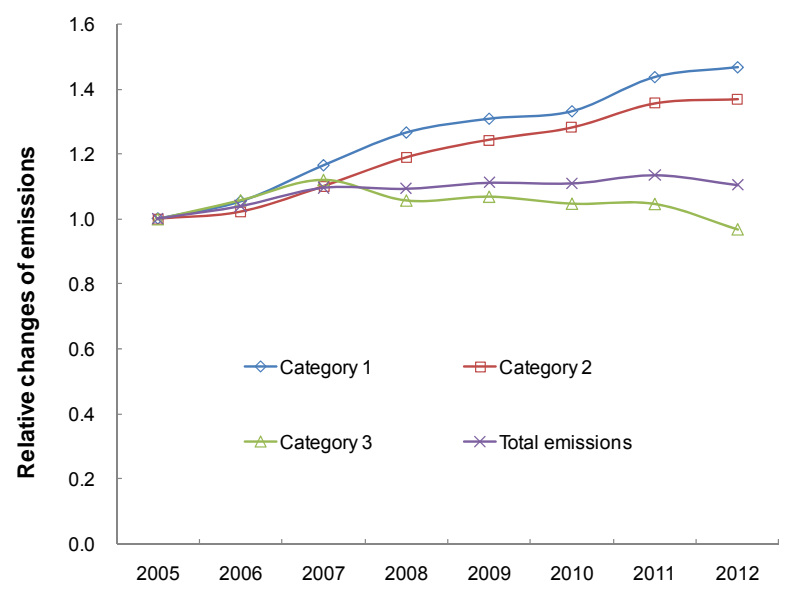

(a)

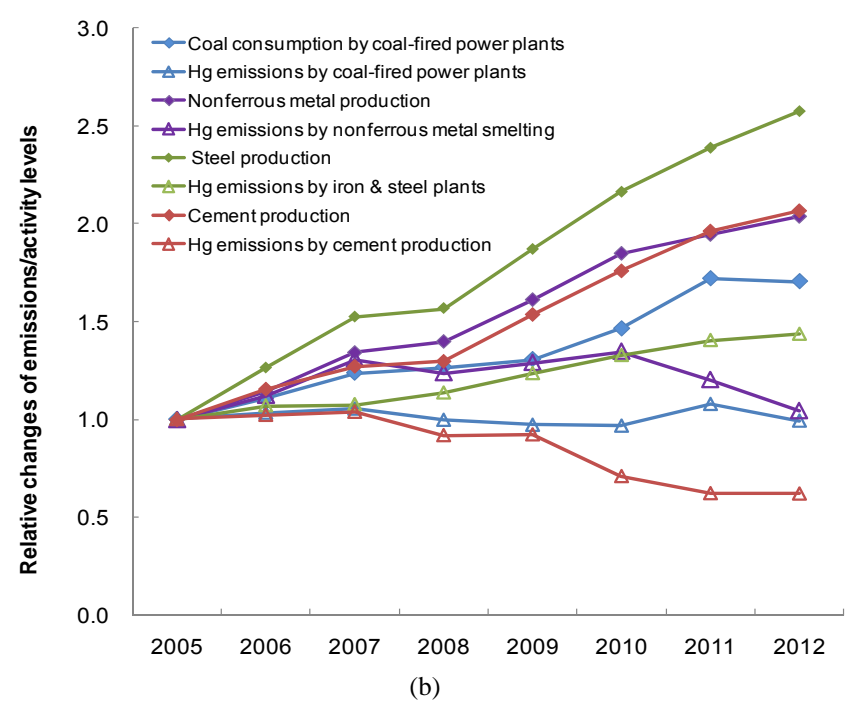

Figure 5. (a) Relative changes in $\mathrm{Hg}$ emissions of the national total and different source categories, and (b) relative changes in $\mathrm{Hg}$ emissions and activity levels for given sectors (all values normalized to the levels in 2005).

through the period are the main reasons for the emission abatement, attributed to the replacement of old and small plants or kilns with larger ones with high combustion efficiencies and advanced control technologies. The increased penetrations of FGD and SCR systems in CPP, precalciner kilns with FF in CEM, mechanized coking ovens with ESP in ISP, and improved manufacturing technologies in NMS have lead to great ancillary benefits of atmospheric $\mathrm{Hg}$ emission abatement. As indicated in Fig. S3 in the Supplement, the emission controls are estimated to have cut 100, 93, 30, and $76 \mathrm{t}$ of $\mathrm{Hg}$ emissions in 2012 for CPP, CEM, ISP and NMS, respectively, compared to a hypothetical case in which no progress of emission control is assumed for the four sectors since 2005. Without the controls, the $\mathrm{Hg}$ emissions of those sectors in 2012 would have exceeded $600 \mathrm{t}$, almost double the current estimate. This shows that China's pollution controls in power and key industrial sectors have slowed national $\mathrm{Hg}$ emissions, and that energy consumption and industrial production are poor proxies for $\mathrm{Hg}$ emissions.

\subsection{Evaluation of the estimated emissions against other studies}

There are several global inventories that include data for China, including those by the United Nations Environment Programme (AMAP/UNEP, 2008, 2013; Pacyna et al., 2010), International Institute for Applied System Analysis (IIASA, Rafaj et al., 2013), Emission Database for Global Atmospheric Research (EDGAR, Muntean et al., 2014), and Peking University (Y. Chen et al., 2013). The trends in China's $\mathrm{Hg}$ emissions estimated in the current work is difficult to compare directly to those studies for two reasons: (1) limited studies have been conducted of China's national total $\mathrm{Hg}$ emissions for the most recent years, a period with large changes in emission controls across the country; and (2) the sectors and sources of anthropogenic Hg emissions are not defined similarly in different inventories. For earlier years, Wu et al. (2006) estimated China's anthropogenic $\mathrm{Hg}$ emissions increased from $552 \mathrm{t}$ in 1995 to $696 \mathrm{t}$ in 2003 , with a higher annual growth rate $(2.9 \%)$ than this work for 2005 $2012(1.4 \%)$. The results of speciation analysis are similar between Wu et al. (2006) and this work, with slightly larger mass fraction of $\mathrm{Hg}^{\mathrm{p}}$ (12 vs. $6 \%$ ) but a smaller one of $\mathrm{Hg}^{2+}$ (32 vs. $39 \%$ ) in $\mathrm{Wu}$ et al. (2006). This is probably due to oxidation of $\mathrm{Hg}^{0}$ by APCDs and increased use of advanced dust collectors after 2005.

Illustrated in Fig. 3 are the estimates of China's anthropogenic $\mathrm{Hg}$ emissions for various years between 2005 and 2012 from different inventories. (Note that estimates by Y. Chen et al. (2013) are not shown because that study included only combustion sources, not all anthropogenic sources.) Our estimates are generally larger than those of global inventories, except for the results of UNEP for 2005 (AMAP/UNEP, 2008). In particular, the estimates for 20052008 by Muntean et al. (2014) are clearly below the lower bounds of $95 \%$ confidence intervals (CI) of this work (see Sect. 4.4 for details). Our higher estimate is supported by limited top-down studies, e.g., Pan et al. (2007), who applied an inverse modeling method with four-dimensional variational data assimilation and derived a larger $\mathrm{Hg}^{0}$ emission estimate than those from bottom-up methods. Most recent studies evaluated the annual emissions of China's anthropogenic $\mathrm{Hg}$ at 643 t for 2007 (Wang et al., 2014) and $494 \mathrm{t}$ for 2008 (Muntean et al., 2014), i.e., 101 and $248 \mathrm{t}$ smaller than our estimates, respectively. Wang et al. (2014) and Muntean et al. (2014) further applied their emissions in GEOS-Chem model and the simulated ambient total $\mathrm{Hg}$ or $\mathrm{Hg}^{0}$ concentrations were generally lower than observation at background/rural sites across the country, implying a possible underestimate of $\mathrm{Hg}$ emissions. 
To better understand the reasons for the discrepancies of various studies, the emissions from particular sectors in global inventories and in this work are summarized and compared in Table S8 in the Supplement. For 2005, the much higher emissions of CPP and the combined HB and OIB sectors in the UNEP inventory (AMAP/UNEP, 2008; Pacyna et al., 2010) than ours estimates mainly from little consideration of emission controls and thereby larger emission factors for those sources. For 2010, however, lower emissions of CPP are estimated in the UNEP inventory (AMAP/UNEP, 2013), attributed mainly to both higher penetrations and higher $\mathrm{Hg}$ removal efficiencies of APCDs compared to our estimates. The large differences in emissions from HB and OIB and NMS are the main sources of higher national totals in our inventory than most of the other global inventories. For example, AMAP/UNEP (2013) uses the energy data from the International Energy Agency, which estimates coal consumption of China's industrial boilers as $110 \mathrm{Mt}$ lower than the official data used here for 2010. FF systems, which are able to capture some $\mathrm{Hg}$ emissions, are assumed to be deployed at $25 \%$ of Chinese industrial boilers by AMAP/UNEP (2013), while our data indicates a much lower penetration. For NMS, AMAP/UNEP (2013) and Muntean et al. (2014) apply activity data from USGS (2011), which provides lower nonferrous metal production estimates than NBS (2013b). Muntean et al. (2014) use emission factors from EMEP/EEA (2009), i.e., $5 \mathrm{~g} \mathrm{t}^{-1} \mathrm{Zn}, 0.9 \mathrm{~g} \mathrm{t}^{-1} \mathrm{~Pb}$, and $0.03 \mathrm{~g} \mathrm{t}^{-1} \mathrm{Cu}$, much lower than our results.

Besides the total emissions, several studies have been conducted to analyze the $\mathrm{Hg}$ emissions from certain sectors in China. For coal combustion sources as a whole, Tian et al. (2010) calculated the $\mathrm{Hg}$ emissions at 284 and $306 \mathrm{t}$ for 2005 and 2007, respectively, within $10 \%$ of our estimates. Y. Chen et al. (2013) calculated China's Hg emissions from coal combustion at $362 \mathrm{t}$ for 2007 , of which the emissions from CPP were $204 \mathrm{t}$, much larger than our estimate of $152 \mathrm{t}$. From a global perspective, Y. Chen et al. (2013) estimated the penetrations of APCD by country using a parameterized function, and derived relatively low fractions of APCD for the power sector in China. Streets et al. (2009b) calculated the emissions from CPP at $125 \mathrm{t}$ for 2005 , while Tian et al. (2012) estimated that annual emissions from CPP during 2005-2007 ranged from 135 to $139 t$, with little inter-annual variability. Those estimates are somewhat lower than our results. Although the differences could be attributed to many factors including discrepancies in details regarding boiler technologies and data sources of $\mathrm{Hg}$ content of coal, the relatively conservative removal efficiencies of APCDs for $\mathrm{Hg}$ assessed and applied by us (as shown in Fig. 2) are believed to be the most important reason for the higher estimate of $\mathrm{Hg}$ emissions. Wang et al. (2010c) estimated that $\mathrm{Hg}$ emissions from CPP would reach $155 \mathrm{t}$ in 2010, higher than our results. However, the energy data and penetrations of APCDs (especially FGD) in Wang et al. (2010c) were predictions based on Zhao et al. (2008), as the official statistics for 2010 were unavailable when the study was conducted. The larger annual coal consumption by CPP and lower penetration of FGDs in the study compared to the official statistics (1735 vs. $1576 \mathrm{Mt}$, and 70 vs. $86 \%$, respectively) could lead to an overestimate of $\mathrm{Hg}$ emissions for the sector.

For NMS, previous inventories commonly used constant emission factors, citing a lack of detailed analyses of the trends in manufacturing technology penetration and thereby any ancillary effects on $\mathrm{Hg}$ emissions. Feng et al. (2009) summarized results from previous studies and estimated that the emission factors of NMS in China for 1995-2003 could reach as high as 6-155 $\mathrm{g} \mathrm{t}^{-1} \mathrm{Zn}, 44 \mathrm{~g} \mathrm{t}^{-1} \mathrm{~Pb}$, and $10 \mathrm{~g} \mathrm{t}^{-1} \mathrm{Cu}$, while Pirrone et al. (2010) adopted $7 \mathrm{~g} / \mathrm{t} \mathrm{Zn,} 3 \mathrm{~g} \mathrm{t}^{-1} \mathrm{~Pb}$, and $5 \mathrm{~g} \mathrm{t}^{-1} \mathrm{Cu}$ for a 2003 emission estimate for China, based on results from developed countries. If those two sets of EF values are applied while ignoring possible variation over time, $\mathrm{Hg}$ emissions from NPS in 2012 would be 475 and $80 \mathrm{t}$, i.e., $420 \%$ larger and $12 \%$ lower than this work, respectively. The big gaps between different estimates, as indicated in Fig. 6a, reveal the importance of better tracking the interannual trends of emission factors for the sector. Based on a detailed survey on individual smelting plants, a more recent study by Wu et al. (2012) developed a technology-based methodology with consideration of smelting processes, mercury concentrations in ore concentrates, and mercury removal efficiencies of APCDs. They calculated that emissions declined from $87 \mathrm{t}$ in 2005 to $72 \mathrm{t}$ in 2010 , more consistent with our study than those using constant emission factors.

For ISP and CEM, emission factors in previous inventories were mainly obtained from Pacyna and Pacyna (2002) and Streets et al. (2005), respectively, i.e., $0.04 \mathrm{~g} \mathrm{t}^{-1}$ product. With these uniform emission factors adopted, estimated $\mathrm{Hg}$ emissions from the two sectors during 2005-2012 would continue increasing from 15 to $38 \mathrm{t}$ and 43 to $88 \mathrm{t}$, respectively, as shown in Fig. $6 \mathrm{~b}$ and c. This ignores the effects of improved manufacturing technologies and increased use of APCDs, and would potentially overestimate emissions, particularly in recent years. For MSWI, the emission factor of $2.8 \mathrm{~g} \mathrm{t}^{-1}$ from UNECE/EMEP (2007) was widely accepted in previous inventories. A series of domestic field measurements, however, suggested a much smaller value of $0.22 \mathrm{~g} \mathrm{t}^{-1}$ for China (L. Chen et al., 2013; Hu et al., 2012), and lower emissions are estimated in this work (Fig. 6d). Given the swift growth of solid wastes in China, more field tests on both municipal and rural solid waste burning plants are thus imperative to confirm the levels of emission factors and to reduce the uncertainties of $\mathrm{Hg}$ emission estimates for these sources.

\subsection{Uncertainties of national emission inventory}

The uncertainties of anthropogenic $\mathrm{Hg}$ emissions in China for 2005-2012 are quantified using Monte Carlo simulation and the results for selected years are summarized in Table 4 . In 2010, for example, the uncertainties of total Hg emissions 


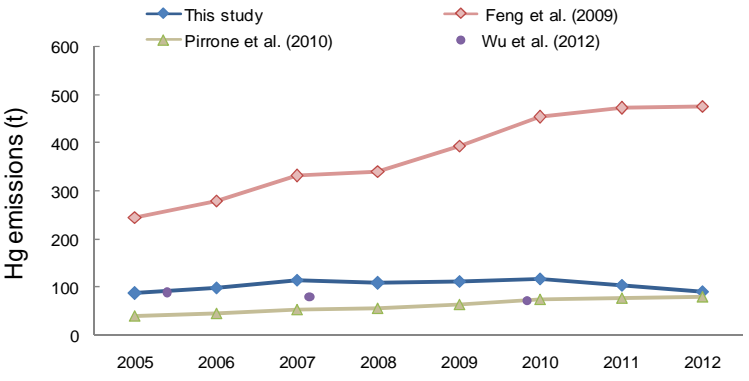

(a) Non-ferrous metal smelting

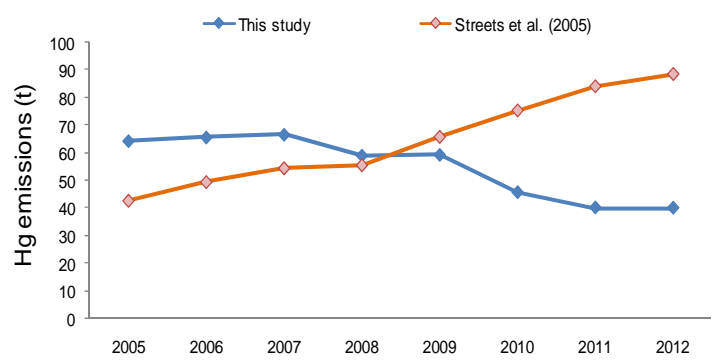

(c) Cement production

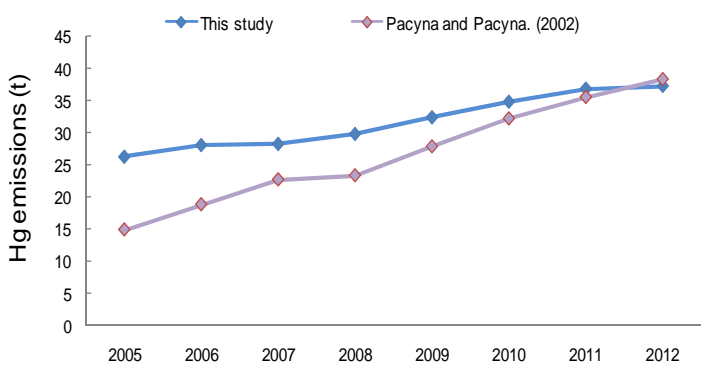

(b) Iron \& steel production

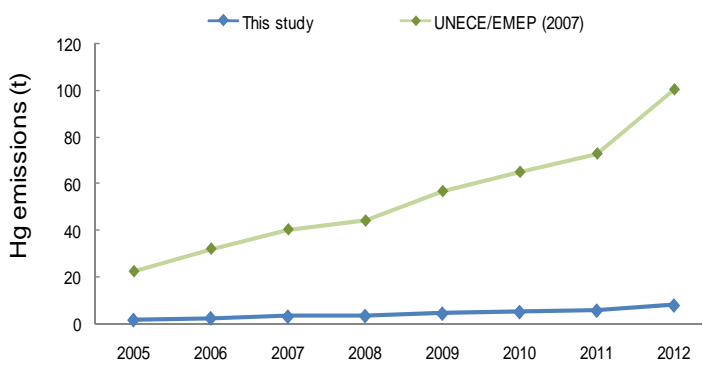

(d) Municipal waste incineration

Figure 6. Comparison of current $\mathrm{Hg}$ emission estimates to those without updated time-variant emission factors for (a) nonferrous metal smelting, (b) iron and steel production, (c) cement production, and (d) solid waste incineration.

Table 4. Uncertainties in Hg emissions by sector for 2005, 2008, 2010 and 2012, expressed as the $95 \%$ confidence intervals of central estimates. The unit for emissions is metric tons $(\mathrm{t})$.

\begin{tabular}{lllll}
\hline & 2005 & 2008 & 2010 & 2012 \\
\hline CPP & $145(-48 \%,+73 \%)$ & $144(-50 \%,+70 \%)$ & $140(-51 \%,+77 \%)$ & $144(-50 \%,+89 \%)$ \\
IND & $473(-30 \%,+43 \%)$ & $534(-27 \%,+46 \%)$ & $543(-26 \%,+51 \%)$ & $527(-27 \%,+54 \%)$ \\
RES & $61(-36 \%,+144 \%)$ & $64(-35 \%,+127 \%)$ & $71(-34 \%,+123 \%)$ & $79(-35 \%,+115 \%)$ \\
\hline Total & $679(-26 \%,+46 \%)$ & $742(-24 \%,+46 \%)$ & $753(-23 \%,+51 \%)$ & $750(-23 \%,+53 \%)$ \\
Total ${ }^{*}$ & $512(-25 \%,+55 \%)$ & $575(-24 \%,+56 \%)$ & $586(-23 \%,+61 \%)$ & $583(-24 \%,+65 \%)$ \\
Coal & $296(-48 \%,+70 \%)$ & $330(-49 \%,+66 \%)$ & $341(-49 \%,+69 \%)$ & $364(-48 \%,+76 \%)$ \\
\hline
\end{tabular}

* Emissions from ASGM excluded.

and those from coal combustion are estimated at $-23-+51 \%$ $(95 \%$ CI) and $-49-+69 \%$, respectively. Since the annual emissions from ASGM and associated uncertainties are assumed to be unchanged during the period and are thus comparatively subjective, the uncertainties of anthropogenic $\mathrm{Hg}$ emissions excluding ASGM is further calculated, at -23$+61 \%$ (95\% CI). The uncertainties of the current $\mathrm{Hg}$ emission inventory are believed to be partly responsible for the differences in ambient $\mathrm{Hg}$ levels between observations and model simulations (e.g., a 0-50\% difference suggested by Wang et al., 2014). Larger uncertainties are found for individual $\mathrm{Hg}$ species than for total $\mathrm{Hg}$, e.g., $-31-+58 \%,-32-$ $+69 \%$, and $-51-+114 \%\left(95 \% \mathrm{CIs}\right.$ ) for $\mathrm{Hg}^{0}, \mathrm{Hg}^{2+}$, and $\mathrm{Hg}^{\mathrm{P}}$ in 2010, respectively (not shown in the table). Among the three aggregate sectors (CPP, IND, and RES), the un- certainties of IND are relatively small. This does not imply that the emission characteristics of IND are well understood, however, but rather results from the aggregation of the uncertainties of all industrial sources. It thus cannot reflect larger uncertainties for particular IND sources.

Figure S4 illustrates the emission estimates and uncertainties by source for different $\mathrm{Hg}$ species in 2010. For all species, BIO, SWI and ROG are the sources with the largest estimated uncertainty relative to their central estimates (i.e., $95 \%$ CIs expressed in percentages). However, particular industrial sources, including those with less relative uncertainty, are better determinants of the national $\mathrm{Hg}$ emission uncertainty, because of their large fractions of total emissions. Those sources include CPP for $\mathrm{Hg}^{0}$, NMS and GM for $\mathrm{Hg}^{0}$ and $\mathrm{Hg}^{2+}$, and OIB and $\mathrm{RC}$ for $\mathrm{Hg}^{\mathrm{P}}$. 
Table 5. The parameters contributing most to emission uncertainties by sector for 2010. The percentages in the parentheses indicate the contributions of the parameters to the variance of corresponding emission estimates.

\begin{tabular}{|c|c|c|c|}
\hline & CPP & IND & RES \\
\hline \multirow{2}{*}{$\mathrm{Hg}$} & $\eta_{\mathrm{ESP}+\mathrm{FGD}}(26 \%)$ & $E_{\mathrm{ASGM}}(41 \%)$ & $\mathrm{EF}_{\text {straw }}(26 \%)$ \\
\hline & $\mathrm{HgC}_{\text {Shandong }}(21 \%)$ & EF $_{\text {NMS_Zn, EP }}(17 \%)$ & $\mathrm{AL}_{\text {coal }}(14 \%)$ \\
\hline \multirow{2}{*}{$\mathrm{Hg}^{0}$} & $\mathrm{HgC}_{\text {Shandong }}(18 \%)$ & $E_{\mathrm{ASGM}}(39 \%)$ & $\mathrm{EF}_{\text {straw }}(41 \%)$ \\
\hline & $\mathrm{HgC}_{\text {Henan }}(8 \%)$ & $f_{\mathrm{GM}, \mathrm{Hg}^{2+}}(19 \%)$ & $\mathrm{AL}_{\text {straw }}(12 \%)$ \\
\hline \multirow{2}{*}{$\mathrm{Hg}^{2+}$} & $\mathrm{HgC}_{\text {Shandong }}(20 \%)$ & $f_{\mathrm{GM}, \mathrm{Hg}^{2+}}(28 \%)$ & $\mathrm{HgC}_{\text {waste }}(28 \%)$ \\
\hline & $f_{\mathrm{ESP}+\mathrm{FGD}, \mathrm{Hg}^{2+}}(13 \%)$ & $\mathrm{EF}_{\mathrm{NMS} \_Z n, E P}(22 \%)$ & $f_{\mathrm{NOC}, \mathrm{Hg}^{2+}}(8 \%)$ \\
\hline \multirow{2}{*}{$\mathrm{Hg}^{\mathrm{p}}$} & 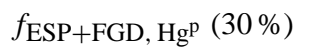 & $f_{\mathrm{WET}, \mathrm{Hg}}(74 \%)$ & $\operatorname{AL}_{\text {coal }}(22 \%)$ \\
\hline & $f_{\mathrm{FF}, \mathrm{Hg}} \mathrm{p}(14 \%)$ & $\mathrm{HgC}_{\text {Shandong }}(4 \%)$ & $f_{\mathrm{NOC}, \mathrm{Hg}^{0}}(15 \%)$ \\
\hline
\end{tabular}

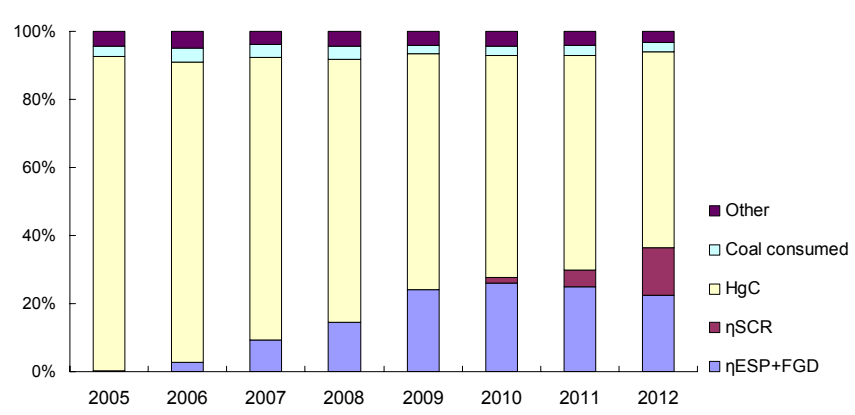

Figure 7. Contribution of different parameters to the variance of $\mathrm{Hg}$ emissions from CPP during 2005-2012.

Table 5 summarizes the parameters that are important in determining the uncertainties of emissions according to their contributions to the variance of emissions. In most cases, parameters related to emission factors contribute most to the uncertainties, including the $\mathrm{Hg}$ content of coal in provinces with large consumption (e.g., Shandong and Henan), emission factors of biomass burning and particular technologies for nonferrous metal smelting, and the removal efficiencies of dominant APCDs. The amount of burned coal and biomass are found to be important specifically to the emission uncertainty of the residential sector. For individual species, the mass fractions of different species for various APCDs and gold mining are identified as key determinants of uncertainty.

It should be noted that no inter-annual variation for those parameters related to emission factors is assumed for the research period, even if large uncertainty exists for them in a given year. Thus, each individual parameter or emission factor applied for estimation of emission uncertainties for a given year is statistically correlated with it for another year in the Monte Carlo simulation framework. Under this ideal assumption, the uncertainties in emissions for an individual year, whether big or small, are not associated with the interannual trends in emissions.
Inclusion of more results from recent measurements of emission factors reduces the uncertainty of CPP for 2005 estimated here compared to that estimated for 2003 by Wu et al. (2010). It can be seen from Table 4, however, that the uncertainties of emissions from CPP increased from 2005 to 2012. This results mainly from the fast penetration of FGD systems after 2005 and that of SCR after 2010, of which the ancillary effects on $\mathrm{Hg}$ control varied significantly among measured plants. In past years, installed FGD systems were believed to be operated sporadically, in order to save operational costs, and large discrepancies in estimated $\mathrm{SO}_{2}$ removal efficiencies exist across the country (Xu, 2011; Zhao et al., 2013, 2014). The unclear operation of FGD causes a wide range of estimated $\mathrm{Hg}$ removal efficiencies of the systems and thus enhances the uncertainties of the emission estimate, as FGD usage increases in the sector over the study period. In addition, the $\mathrm{Hg}$ removal effects of SCR are still poorly quantified, and the uncertainties of $\mathrm{Hg}$ emissions are further elevated in recent years because China is currently undertaking $\mathrm{NO}_{x}$ control largely through expanded use of SCR (Zhao et al., 2014). As shown in Fig. 7, the contribution of $\mathrm{Hg}$ removal efficiency of FGD to the variance of CPP emissions increases from $0 \%$ in 2005 to $26 \%$ in 2010 , and it has been the most important parameter contributing to the uncertainty of CPP emissions since 2009. In 2012, $\mathrm{Hg}$ removal efficiencies of FGD and SCR are estimated to collectively contribute $37 \%$ of the uncertainty of $\mathrm{Hg}$ emissions. The emission uncertainties of given industrial sources increased recently for similar reasons. The uncertainty of $\mathrm{Hg}$ emissions from NMS, for example, increased from -46$+116 \%$ in 2005 to $-45-+169 \%$ in 2012 . This is attributed mainly to the increased use of electrolytic processes in zinc smelting, for which domestic measurements are rare and the emission factor has high uncertainty. Moreover, the reduced ratios of gold extraction by amalgamation, reported but unconfirmed, enhance the $\mathrm{Hg}$ emission uncertainty of gold mining. In general, therefore, the uncertainty of $\mathrm{Hg}$ emissions is higher in the most recent years and may continue to be so in 
Table 6. Projected national $\mathrm{Hg}$ emissions by source category for different scenarios through 2030.

\begin{tabular}{|c|c|c|c|c|c|c|c|c|c|}
\hline \multirow[t]{2}{*}{ Source category } & \multicolumn{3}{|c|}{2015} & \multicolumn{3}{|c|}{2020} & \multicolumn{3}{|c|}{2030} \\
\hline & So & $\mathrm{S} 1$ & $\mathrm{~S} 2$ & So & $\mathrm{S} 1$ & $\mathrm{~S} 2$ & So & $\mathrm{S} 1$ & $\mathrm{~S} 2$ \\
\hline Coal-fired power plants & 150.0 & 149.6 & 130.8 & 164.2 & 153.1 & 130.9 & 181.8 & 155.0 & 126.8 \\
\hline Industry & 578.1 & 571.1 & 405.4 & 588.0 & 580.9 & 401.4 & 570.9 & 547.6 & 342.5 \\
\hline Cement production & 36.8 & 36.6 & 25.4 & 37.5 & 37.3 & 17.2 & 25.0 & 24.3 & 8.9 \\
\hline Coal use & 21.1 & 21.0 & 13.2 & 21.7 & 21.6 & 11.3 & 17.6 & 17.3 & 8.7 \\
\hline Iron and steel plants & 40.0 & 39.9 & 39.3 & 41.7 & 41.4 & 39.0 & 39.8 & 39.1 & 34.8 \\
\hline Heating boilers & 39.2 & 37.8 & 34.2 & 38.8 & 37.4 & 33.8 & 40.8 & 36.1 & 32.3 \\
\hline Other industrial boilers & 105.2 & 101.3 & 86.4 & 104.1 & 100.4 & 85.4 & 109.4 & 96.8 & 81.7 \\
\hline Nonferrous metal smelting & 110.5 & 109.6 & 102.4 & 116.0 & 115.0 & 105.5 & 109.6 & 106.8 & 68.2 \\
\hline Zinc & 84.5 & 83.8 & 78.9 & 88.7 & 88.0 & 81.8 & 83.8 & 81.7 & 56.0 \\
\hline Lead & 24.7 & 24.5 & 22.3 & 25.9 & 25.7 & 22.4 & 24.5 & 23.9 & 11.0 \\
\hline Copper & 1.3 & 1.3 & 1.2 & 1.4 & 1.3 & 1.3 & 1.3 & 1.3 & 1.2 \\
\hline Gold mining & 182.5 & 182.4 & 63.3 & 183.3 & 183.1 & 63.7 & 182.4 & 182.0 & 63.2 \\
\hline Large scale & 15.5 & 15.4 & 7.7 & 16.3 & 16.1 & 8.1 & 15.4 & 15.0 & 7.5 \\
\hline Artisanal and small scale & 167.0 & 167.0 & 55.7 & 167.0 & 167.0 & 55.7 & 167.0 & 167.0 & 55.7 \\
\hline Other miscellaneous processes & 64.0 & 63.5 & 54.3 & 66.6 & 66.1 & 56.7 & 63.9 & 62.6 & 53.4 \\
\hline Mercury mining & 34.1 & 33.8 & 33.8 & 35.8 & 35.5 & 35.5 & 33.8 & 33.0 & 33.0 \\
\hline Battery/fluorescent lamp production & 10.0 & 10.0 & 3.3 & 10.0 & 10.0 & 3.3 & 10.0 & 10.0 & 3.3 \\
\hline PVC production & 16.8 & 16.7 & 14.1 & 17.7 & 17.5 & 14.8 & 16.7 & 16.3 & 13.7 \\
\hline Oil and gas combustion & 3.0 & 3.0 & 3.0 & 3.2 & 3.1 & 3.1 & 3.3 & 3.3 & 3.3 \\
\hline Residential and commercial sector & 86.0 & 84.2 & 84.2 & 92.0 & 88.4 & 88.4 & 116.7 & 109.9 & 109.9 \\
\hline Coal burning & 37.9 & 37.0 & 37.0 & 37.3 & 36.4 & 36.4 & 34.6 & 31.6 & 31.5 \\
\hline Biofuel use/biomass open burning & 8.7 & 8.7 & 8.7 & 8.1 & 8.1 & 8.1 & 6.6 & 6.6 & 6.6 \\
\hline Solid waste incineration & 20.7 & 20.7 & 20.7 & 24.6 & 24.6 & 24.6 & 49.7 & 49.7 & 49.7 \\
\hline Municipal & 13.9 & 13.9 & 13.9 & 18.5 & 18.5 & 18.5 & 45.1 & 45.1 & 45.1 \\
\hline Rural & 6.8 & 6.8 & 6.8 & 6.1 & 6.1 & 6.1 & 4.6 & 4.6 & 4.6 \\
\hline Oil and gas combustion & 18.7 & 17.8 & 17.8 & 22.0 & 19.3 & 19.3 & 25.8 & 22.0 & 22.0 \\
\hline Total & 814.1 & 805.0 & 620.4 & 844.3 & 822.5 & 620.7 & 869.3 & 812.5 & 579.1 \\
\hline Total coal combustion & 393.3 & 386.7 & 340.9 & 407.9 & 390.4 & 336.9 & 423.9 & 375.9 & 315.8 \\
\hline
\end{tabular}

the near future. More field tests or investigations of particularly important sectors are needed for better understanding of the evolution of emission sources and their benefits to $\mathrm{Hg}$ control.

\subsection{Future emission trends by scenarios}

The projected national emissions through 2030 are summarized by sector in Table 6. As shown in Fig. 3 and Table 6, China's anthropogenic $\mathrm{Hg}$ emissions are likely to increase slightly in the future, even with a few new $\mathrm{Hg}$-specific control measures, judged by scenarios S0 and S1. The emissions in 2030 for the two scenarios are estimated at 869 and 813 t, i.e., 16 and $8 \%$ higher than 2012 , respectively. The estimated growth in $\mathrm{Hg}$ emissions continues to be slower than that of the economy and energy consumption projected by IEA (2012). This results mainly from the ancillary benefits of ongoing control policies targeting other pollutants in the country, such as the National Action Plan for Air Pollution Prevention and Control (Zhao et al., 2014). The results sug- gest that projecting China's Hg trajectory based only on economic and/or energy growth would likely lead to overestimation.

Comparing the three scenarios, $\mathrm{S} 2$ produces a much larger reduction in $\mathrm{Hg}$ emissions over $\mathrm{S} 0$ than does $\mathrm{S} 1$. This suggests that implementation of $\mathrm{Hg}$-specific controls may offer more effective emission reduction than relying on the ancillary benefits of energy conservation. In particular, if key industrial sources including ASGM can be controlled by national regulations (two thirds of such emissions are assumed to be cut in S2, based on an estimate by Feng et al., 2009), the national $\mathrm{Hg}$ emissions from 2015 on would be less than those of 2005, and by 2030 would be less than 600 t, $23 \%$ below the 2012 total. For industrial sources other than metallurgy, however, the $\mathrm{Hg}$ abatement in $\mathrm{S} 2$ is relatively modest, implying small future ancillary effects on $\mathrm{Hg}$ of APCDs due to their nearly saturated deployment in most sectors. Expanded use of Hg-specific removal devices in sectors such as power generation and heavy industry is thus essential to further reduce $\mathrm{Hg}$ emissions in the future. In addition, very few 
effective policies are identified that target residential sources, resulting in elevated emissions for that sector. The RES share of total anthropogenic $\mathrm{Hg}$ emissions in $\mathrm{S} 2$ is thus projected to rise from $11 \%$ in 2012 to $19 \%$ in 2030 .

\section{Conclusions}

Facing difficult challenges of severe urban and regional air pollution driven by swift economic development and enormous energy consumption, China has been implementing a series of policies in energy conservation and emission control since 2005. Although not specifically targeting $\mathrm{Hg}$, a pollutant of broad international concern, the policies and measures have effectively constrained China's $\mathrm{Hg}$ emissions because of their ancillary effects. From 2005 to 2012, China's anthropogenic emissions of atmospheric $\mathrm{Hg}$ are estimated to have increased from 679 to $750 \mathrm{t}$, a much slower rate of growth than those of China's economy and energy consumption. The values are generally larger than those of global inventories, as higher activity levels (energy consumption and industrial production) and lower penetrations of emission control devices for certain industrial sources are applied in this study. Decreased $\mathrm{Hg}$ emissions are estimated for the JJJ, YRD, and PRD regions, the areas of the country with the highest density of population, economic activity, and energy consumption. The collective $\mathrm{Hg}$ emissions from four key sectors (power generation, cement production, iron and steel production, and nonferrous metal smelting) are estimated to decline $3 \%$ from 2005 to 2012, attributed to the enhanced use of devices with high energy efficiencies and pollutant removal rates. Even with considerable growth of energy use projected by IEA (2012), continued measures in pollution control will further constrain the national $\mathrm{Hg}$ emission trajectory in the future. Analyses that overlook the effects of recent energy and pollution control policies will thus likely result in overestimation of China's recent and future $\mathrm{Hg}$ emissions.

It should be noted, however, that the uncertainties of China's $\mathrm{Hg}$ emission estimate have at the same time increased in recent years. This is mainly because of high uncertainties about the operational and other characteristics of the same advanced APCDs or improved manufacturing technologies that are nevertheless believed to be reducing emissions in key sectors. In addition, the unknown levels and locations of illegal ASGM activities continue to contribute significantly to the uncertainty of China's $\mathrm{Hg}$ emissions. Beyond interest in the national $\mathrm{Hg}$ emission totals, the relatively poor understanding of the speciation of $\mathrm{Hg}$ by sector elevates the uncertainties of emissions of different species, which are of particular importance to scientists simulating atmospheric transport, chemistry, and the environmental fate of $\mathrm{Hg}$. Given the ongoing dramatic changes of emission sources under current policies within the country, therefore, systematic investigations by sector are suggested for $\mathrm{Hg}$ pollution, to better track the variability of emission levels and efficiently reduce the uncertainty of emissions for all $\mathrm{Hg}$ species. Middle- to long-term observations of atmospheric $\mathrm{Hg}$, both in polluted urban and regional background areas, are also needed to validate analyses of China's anthropogenic $\mathrm{Hg}$ emission and to confirm the beneficial effects of pollution control implementation in the country.

\section{The Supplement related to this article is available online at doi:10.5194/acp-15-4317-2015-supplement.}

Acknowledgements. This work was sponsored by the Natural Science Foundation of China (41205110), the Natural Science Foundation of Jiangsu (BK20140020 and BK2012310), and the Ministry of Education of China (20120091120019). We would like to thank Shuxiao Wang and Qingru Wu from Tsinghua University for providing detailed technology information on non-ferrous metal smelting, Simon Wilson from the Arctic Monitoring and Assessment Programme for providing information and data on emissions from artisanal gold mining, and Shigeru Suehiro from the International Energy Agency for providing data for Chinese energy and industrial projections. Thanks also go to three anonymous reviewers for their very valuable comments to improve this work.

Edited by: G. Frost

\section{References}

AGC (Artisanal Gold Council): Global Database on Mercury Emissions from Artisanal and Small Scale Mining (ASGM), available at: http://www.mercurywatch.org (last access: 27 April 2015), 2010.

AMAP/UNEP: Technical Background Report to the Global Atmospheric Mercury Assessment, Arctic Monitoring and Assessment Programme, Oslo, Norway/UNEP Chemicals Branch, Geneva, Switzerland, 159 pp., 2008.

AMAP/UNEP: Technical Background Report for the Global Mercury Assessment 2013, Arctic Monitoring and Assessment Programme, Oslo, Norway/UNEP Chemicals Branch, Geneva, Switzerland, 263 pp., 2013.

Bond, T. C., Streets, D. G., Yarber, K. F., Nelson, S. M., Woo, J. H., and Klimont, Z.: A technology-based global inventory of black and organic carbon emissions from combustion, J. Geophys. Res., 109, D14203, doi:10.1029/2003jd003697, 2004.

Chen, C., Wang, H., Zhang, W., Hu, D., Chen, L., and Wang, X.: High-resolution inventory of mercury emissions from biomass burning in China for 2000-2010 and a projection for 2020, J. Geophys. Res., 118, 12248-12256, 2013.

Chen, L., Liu, M., Fan, R., Ma, S., Xu, Z., Ren, M., and He, Q.: Mercury speciation and emission from municipal solid waste incinerators in the Pearl River Delta, South China, Sci. Total Environ., 447, 396-402, 2013.

Chen, Y., Wang, R., Shen, H., Li, W., Chen, H., Huang, Y., Zhang, Y., Chen, Y., Su, S., Lin, N., Liu, J., Li, B., Wang, X., Liu, W. Coveney, R. M., and Tao, S.: Global mercury emissions from 
combustion in light of international fuel trading, Environ. Sci. Technol., 48, 1727-1735, 2013.

China Association of Urban Environmental Sanitation (CAUES): Development Report on China Urban Environmental Sanitation (2012), China City Press, Beijing, 2013 (in Chinese).

Ci, Z., Zhang, X., and Wang, Z.: Enhancing atmospheric mercury research in China to improve the current understanding of the global mercury cycle: the need for urgent and closely coordinated efforts, Environ. Sci. Technol., 46, 5636-5642, 2012.

Corbitt, E. S., Jacob, D. J., Holmes, C. D., Streets, D. G., and Sunderland, E. M.: Global source-receptor relationships for mercury deposition under present-day and 2050 emissions scenarios, Environ. Sci. Technol., 45, 10477-10484, 2011.

Cui, X., Ma, L. P., Deng. C. L., Xu. W. J., and Mao. N.: Research progress of removing mercury from coal-fired flue gas, Chemical Industry and Engineering Progress, 30, 1607-1612, 2011 (in Chinese).

Driscoll, C. T., Mason, R. P., Chan, H. M., Jacob, D. J., and Pirrone, N.: Mercury as a global pollutant: sources, pathways, and effects. Environ. Sci. Technol., 47, 4967-4983, 2013.

EMEP/EEA: EMEP/EEA CORINAIR emission inventory guidebook. Technical report No. 9/2009. European Environment Agency, available at: http://www.eea.europa.eu/publications/ emep-eea-emission-inventory-guidebook-2009, 2009.

Feng, X., Sommer, J., Lindqvist, O., and Hong, Y.: Occurrence, emissions and deposition of mercury during coal combustion in the province Guizhou, China, Water Air Soil Poll., 139, 311-324, 2002.

Feng, X., Li, G., and Qiu, G.: A preliminary study on mercury contamination to the environment from artisanal zinc smelting using indigenous methods in Hezhang county, Guizhou, China-Part 1: mercury emission from zinc smelting and its influences on the surface waters, Atmos. Environ., 38, 6223-6230, 2004

Feng, X., Streets, D. G., Hao, J., Wu, Y., and Li, G.: Mercury emissions from industrial sources in China, in: Mercury Fate and Transport in the Global Atmosphere, edited by: Pirrone, N. and Mason, R. P., Springer US, 67-79, 2009.

Frey, H. C. and Zheng, J. Y.: Quantification of variability and uncertainty in air pollutant emission inventories: method and case study for utility $\mathrm{NO}_{x}$ emissions, J. Air Waste Ma., 52, 10831095, 2002.

Fu, X., Feng, X., Sommar, J., and Wang, S.: A review of studies on atmospheric mercury in China, Sci. Total Environ., 421-422, 73-81, 2012a.

Fu, X. W., Feng, X., Shang, L. H., Wang, S. F., and Zhang, H.: Two years of measurements of atmospheric total gaseous mercury (TGM) at a remote site in Mt. Changbai area, Northeastern China, Atmos. Chem. Phys., 12, 4215-4226, doi:10.5194/acp12-4215-2012, 2012b.

Guo, Y., Yan, N., Yang, S., Qu, Z., Wu Z., Liu, Y., Liu, P., and Jia, J.: Conversion of elemental mercury with a novel membrane delivery catalytic oxidation system, Environ. Sci. Technol., 45, 706-711, 2011.

Hong, B., Zhu, Y., Feng, X., and Wang, Y.: Distribution of mercury in coal gas generating procedure, Earth and Environment, 32, 12 16, 2004 (in Chinese).

Hu, D., Zhang, W., Chen, L., Chen, C., Ou, L., Tong, Y., Wei, W., Long, W., and Wang, X.: Mercury emissions from waste combus- tion in China from 2004 to 2010, Atmos. Environ., 62, 359-366, 2012.

Huang, W. and Yang, Y.: Mercury in coal in China, Coal Geology of China, 14, 37-40, 2002 (in Chinese).

Huang, X., Li, M., Friedli, H. R. Song, Y., Chang, D., and Zhu, L.: Mercury emissions from biomass burning in China, Environ. Sci. Technol., 45, 9442-9448, 2011.

Huang, Y., Jin, B., Zhong, Z., and Xiao, R.: Study on the distribution of trace elements in gasification products, Proceedings of the CSEE, 24, 208-212, 2004 (in Chinese).

International Energy Agency (IEA): World Energy Outlook 2012, International Energy Agency, Paris, France, 2012.

Ito, S., Yokoyama, T., and Asakura, K.: Emissions of mercury and other trace elements from coal-fired power plants in Japan, Sci. Total Environ., 368, 397-402, 2006.

Lei, Y., Zhang, Q., Nielsen, C. P., and He, K. B.: An inventory of primary air pollutants and $\mathrm{CO}_{2}$ emissions from cement industry in China, 1990-2020, Atmos. Environ., 45, 147-154, 2011.

Li, G., Feng, X., and Li, Z.: Atmospheric mercury emissions from retort Zn productions, J. Tsinghua Univ., 49, 2001-2004, 2009 (in Chinese).

Li, G., Feng, X., Li, Z., Qiu, G., Shang, L., Liang, P., Wang, D., and Yang, Y.: Mercury emission to atmosphere from primary Zn production in China, Sci. Total Environ., 408, 4607-4612, 2010.

Li, P., Feng, X., Qiu, G., Shang, L., Wang, S., and Meng, B.: Atmospheric mercury emission from artisanal mercury mining in Guizhou Province, Southwestern China, Atmos. Environ., 43, 2247-2251, 2009.

Li, P., Feng, X., Qiu, G., Shang, L., and Wang, S.: Mercury pollution in Wuchuan mercury mining area, Guizhou, Southwestern China: The impacts from large scale and artisanal mercury mining, Environ. Int., 42, 59-66, 2012.

Li, W.: Characterization of Atmospheric Mercury Emissions from Coal-fired Power Plant and Cement Plant (Master Thesis), Xi'nan University, Chongqing, China, 2011 (in Chinese).

Lin, C.-J., Pan, L., Streets, D. G., Shetty, S. K., Jang, C., Feng, X., Chu, H.-W., and Ho, T. C.: Estimating mercury emission outflow from East Asia using CMAQ-Hg, Atmos. Chem. Phys., 10, 1853-1864, doi:10.5194/acp-10-1853-2010, 2010.

Muntean, M., Jassens-Maenhout, G., Song, S., Selin, N. E., Olivier, J. G. J., Guizzardi, D., Maas, R., and Dentener, F.: Trend analysis from 1970 to 2008 and model evaluation of EDGARv4 global gridded anthropogenic mercury emissions, Sci. Total Environ. 494-495, 337-350, 2014.

National Bureau of Statistics (NBS): China Statistical Yearbook 2005-2012, China Statistics Press, Beijing, 2013a (in Chinese).

National Bureau of Statistics (NBS): China Industry Economy Statistical Yearbook 2005-2012, China Statistics Press, Beijing, 2013b (in Chinese).

National Bureau of Statistics (NBS): China Statistical Yearbook 2005-2012, China Statistics Press, Beijing, 2013c (in Chinese).

Pacyna, E. G. and Pacyna, J. M.: Global emission of mercury from anthropogenic sources in 1995, Water Air Soil Poll., 137, 149165, 2002.

Pacyna, E. G., Pacyna, J. M., Sundseth, K., Munthe, J., Kindbom, K., Wilson, S., Steenhuisen, F., and Maxson, P.: Global emission of mercury to the atmosphere from anthropogenic sources in 2005 and projections to 2020, Atmos. Environ., 44, 2487-2499, 2010. 
Pan, L., Chai, T., Carmihael, G. R., Tang, Y., Streets, D., Woo, J.-H., Friedli, H. R., and Radke, L. F.: Top-down estimate of mercury emissions in China using four-dimensional variational data assimilation, Atmos. Environ., 41, 2804-2819, 2007.

Pan, L., Carmichael, G. R., Adhikary, B., Tang, Y., Streets, D. G., Woo, J. -H., Friedli, H. R., and Radke, L. F.: A regional analysis of the fate and transport of mercury in East Asia and an assessment of major uncertainties, Atmos. Environ., 42, 1144-1159, 2008.

Pirrone, N. and Mason, R. P. (Eds.): Mercury fate and transport in the global atmosphere, Springer US, 2009.

Pirrone, N., Cinnirella, S., Feng, X., Finkelman, R. B., Friedli, H. R., Leaner, J., Mason, R., Mukherjee, A. B., Stracher, G. B., Streets, D. G., and Telmer, K.: Global mercury emissions to the atmosphere from anthropogenic and natural sources, Atmos. Chem. Phys., 10, 5951-5964, doi:10.5194/acp-10-59512010, 2010.

Rafaj, P., Bertok, I., Cofala, J., and Schopp, W.: Scenarios of global mercury emissions from anthropogenic sources, Atmos. Environ., 79, 472-479, 2013.

Slemr, F., Brunke, E.-G., Ebinghaus, R., and Kuss, J.: Worldwide trend of atmospheric mercury since 1995, Atmos. Chem. Phys., 11, 4779-4787, doi:10.5194/acp-11-4779-2011, 2011.

Srivastava, R. K., Hutson, N., Martin, B., Princiotta, F., and Staudt, J.: Control of mercury emissions from coal-fired electric utility boilers, Environ. Sci. Technol., 40, 1385-1393, 2006.

Streets, D. G., Hao, J., Wu, Y. Jiang, J., Chan, M., Tian, H., and Feng, X.: Anthropogenic mercury emissions in China, Atmos. Environ., 39, 7789-7806, 2005.

Streets, D. G., Zhang, Q., and Wu, Y.: Projections of global mercury emissions in 2050, Environ. Sci. Technol., 43, 2983-2988, 2009a.

Streets, D. G., Hao. J., Wang, S., and Wu, Y.: Mercury emissions from coal combustion in China, in: Mercury Fate and Transport in the Global Atmosphere, edited by: Pirrone, N. and Mason, R. P., Springer US, 51-65, 2009b.

Tang, S., Feng, X., Shang, L., Yan, H., and Hou, Y.: Mercury speciation and emissions in the flue gas of a small-scale coal-fired boiler in Guiyang, Research of Environmental Sciences, 17, 74 76, 2004 (in Chinese).

Telmer, K. and Veiga, M.: World emissions of mercury from artisanal and small scale gold mining, in: Mercury Fate and Transport in the Global Atmosphere, edited by: Pirrone, N. and Mason, R. P., Springer US, 131-172, 2009.

Tian, H. Z., Wang, Y., Xue, Z. G., Cheng, K., Qu, Y. P., Chai, F. H., and Hao, J. M.: Trend and characteristics of atmospheric emissions of $\mathrm{Hg}$, As, and Se from coal combustion in China, 1980 2007, Atmos. Chem. Phys., 10, 11905-11919, doi:10.5194/acp10-11905-2010, 2010.

Tian, H. Z., Wang, Y., Cheng, K., Qu, Y., Hao, J, Xue, Z., and Chai, F.: Control strategies of atmospheric mercury emissions from coal-fired power plants in China, J. Air Waste Ma., 62, 576-58, 2012.

United Nations Economic Commission for Europe/The European Monitoring and Evaluation Programme (UNECE/EMEP): Atmospheric Emission Inventory Guidebook, available at: http://www. eea.europa.eu/publications/EMEPCORINAIR5 (last access: 27 April 2015), 2007.
U.S. Environmental Protection Agency (USEPA): Compilation of Air Pollutant Emission Factors (AP-42), available at: http://www. epa.gov/ttn/chief/ap42/index.html (last access: 27 April 2015), 2002a.

U.S. Environmental Protection Agency (USEPA): Characterization and management of residues from coal-fired power plants, Interim Report, EPA-600/R-02-083, 2002b.

U.S. Geological Survey (USGS): Mercury content in coal mines in China, 2004

U.S. Geological Survey (USGS): Commodity Statistics and Information, available at: http://minerals.usgs.gov/minerals/pubs/ commodity (last access: 27 April 2015), 2011.

Wan, Q., Feng, X., Lu, J., Zheng, W., Song, X., Han, S., and Xu, H.: Atmospheric mercury in Changbai Mountain area, northeastern China-Part 1: the seasonal distribution pattern of total gaseous mercury and its potential sources, Environ. Res., 109, 201-206, 2009.

Wang, F.: The control policy for total emission amount of primary pollutants during the 12th Five Year Plan period, presented at the 17th Workshop on $\mathrm{SO}_{2}, \mathrm{NO}_{x}$, and $\mathrm{Hg}$ pollution control technology and $\mathrm{PM}_{2.5}$ control and monitoring technology, Hangzhou, China, 16-17 May 2013.

Wang, K., Wang, C., Lu, X. D., and Chen, J. N.: Scenario analysis on $\mathrm{CO}_{2}$ emissions reduction potential in China's iron and steel industry, Energ. Policy, 35, 2320-2335, 2007.

Wang, L., Wang, S., Zhang, L., Wang, Y., Zhang, Y., Nielsen, C., McElroy, M. B., and Hao, J.: Source apportionment of atmospheric mercury pollution in China using the GEOS-Chem model, Environ. Pollut., 190, 166-175, 2014.

Wang, Q., Shen, W., and Ma, Z.: Estimation of mercury emission from coal combustion in China, Environ. Sci. Technol., 34 2711-2713, 2000

Wang, S. X., Song, J. X., Li, G. H., Wu, Y., Zhang, L., Wan, Q., Streets, D. G., Chin, C. K., and Hao, J. M.: Estimating mercury emissions from a zinc smelter in relation to China's mercury control policies, Environ. Pollut., 158, 3347-3353, 2010a.

Wang, S. X., Zhang, L., Li, G. H., Wu, Y., Hao, J. M., Pirrone, N., Sprovieri, F., and Ancora, M. P.: Mercury emission and speciation of coal-fired power plants in China, Atmos. Chem. Phys., 10, 1183-1192, doi:10.5194/acp-10-1183-2010, $2010 \mathrm{~b}$.

Wang, S. X., Zhang, L., Wu, Y., Ancora, M. P., Zhao, Y., and Hao, J. M.: Synergistic mercury removal by conventional pollutant control strategies for coal-fired power plants in China, J. Air Waste Ma., 60, 722-730, 2010c.

Wang, S. X., Zhang, L., Zhao, B., Meng, Y., and Hao, J. M.: Mitigation potential of mercury emissions from coal-fired power plants in China, Energy Fuels, 26, 4635-4642, 2012.

Wu, Q. R., Wang, S. X., Zhang, L., Song, J. X., Yang, H., and Meng, Y.: Update of mercury emissions from China's primary zinc, lead and copper smelters, 2000-2010, Atmos. Chem. Phys., 12, 11153-11163, doi:10.5194/acp-12-11153-2012, 2012.

Wu, Y., Wang, S., Streets, D. G., Hao, J., Chan, M., and Jiang. J.: Trends in anthropogenic mercury emissions in China from 1995 to 2003, Environ. Sci. Technol., 40, 5312-5318, 2006.

Wu, Y., Streets, D. G., Wang, S. X., and Hao, J. M.: Uncertainties in estimating mercury emissions from coal-fired power plants in China, Atmos. Chem. Phys., 10, 2937-2946, doi:10.5194/acp10-2937-2010, 2010. 
$\mathrm{Xu}, \mathrm{Y} .:$ Improvements in the operation of $\mathrm{SO}_{2}$ scrubbers in China's coal power plants, Environ. Sci. Technol., 45, 380-385, 2011.

Yan, N., Chen, W., Chen, J., Qu, Z., Guo, Y., Yan, S., and Jia, J.: Significance of $\mathrm{RuO} 2$ modified SCR catalyst for elemental mercury oxidation in coal-fired flue gas, Environ. Sci. Technol., 45, 5725-5730, 2011.

Yao, W., Qu, X., Li, H., and Fu, Y.: Production, collection and treatment of garbage in rural areas in China, J. Environ. Health, 26, 10-12, 2009 (in Chinese).

Zhang, L.: Research on mercury emission measurement and estimate from combustion resources (Master Thesis), Zhejiang University, Hangzhou, China, 2007 (in Chinese).

Zhang, L., Zhuo, Y., Chen, L., Xu X., and Chen, C.: Mercury emissions from six coal-fired power plants in China, Fuel Processing Technology, 89, 1033-1040, 2008.

Zhang, L., Wang, S., Meng, Y., and Hao, J.: Influence of mercury and chlorine content of coal on mercury emissions from coalfired power plants in China, Environ. Sci. Technol., 46, 63856392, 2012a.

Zhang, L., Wang, S., Wu, Q., Meng, Y., Yang, H., Wang, F., and Hao, J.: Were mercury emission factors for Chinese non-ferrous metal smelters overestimated? Evidence from onsite measurements in six smelters, Environ. Pollut., 171, 109-117, 2012b.

Zhang, W., Wei, W., Hu, D., Zhu, Y., and Wang, X.: Emission of speciated mercury from residential biomass fuel combustion in China, Energy Fuels, 27, 6792-6800, 2013.

Zhao, Y., Wang, S. X., Duan, L., Lei, Y., Cao, P. F., and Hao, J. M.: Primary air pollutant emissions of coal-fired power plants in China: current status and future prediction, Atmos. Environ., 42, 8442-8452, 2008.
Zhao, Y., Wang, S. X., Nielsen, C. P., Li, X. H., and Hao, J. M.: Establishment of a database of emission factors for atmospheric pollutants from Chinese coal-fired power plants, Atmos. Environ., 44, 1515-1523, 2010.

Zhao, Y., Nielsen, C. P., Lei, Y., McElroy, M. B., and Hao, J.: Quantifying the uncertainties of a bottom-up emission inventory of anthropogenic atmospheric pollutants in China, Atmos. Chem. Phys., 11, 2295-2308, doi:10.5194/acp-11-2295-2011, 2011.

Zhao, Y., Nielsen, C. P., McElroy, M. B., Zhang, L., and Zhang, J.: CO emissions in China: uncertainties and implications of improved energy efficiency and emission control, Atmos. Environ. 49, 103-113, 2012.

Zhao, Y., Zhang, J., and Nielsen, C. P.: The effects of recent control policies on trends in emissions of anthropogenic atmospheric pollutants and $\mathrm{CO}_{2}$ in China, Atmos. Chem. Phys., 13, 487-508, doi:10.5194/acp-13-487-2013, 2013.

Zhao, Y., Zhang, J., and Nielsen, C. P.: The effects of energy paths and emission controls and standards on future trends in China's emissions of primary air pollutants, Atmos. Chem. Phys., 14, 8849-8868, doi:10.5194/acp-14-8849-2014, 2014.

Zheng, L. G., Liu, G. J., Qi, C. C., Chen, Y. W., and Zhang, Y.: Study on environmental geochemistry of mercury in Chinese coals, J. Univers. Sci. Technol. China, 37, 953-963, 2007 (in Chinese).

Zhi, G., Xue, Z., Li, Y., Ma, J., Liu, Y., Meng, F., and Chai, F.: Uncertainty of flue gas mercury emissions from coal-fired power plants in China based on field measurements, Research of Environmental Sciences, 26, 814-821, 2013 (in Chinese). 